\title{
RICARDO VINÓS SANTOS: UN CIENTÍFICO VITORIANO AL SERVICIO DE LA II REPÚBLICA (1888-1959) ${ }^{1}$
}

\author{
David Mota Zurdo \\ Universidad Isabel I, España \\ david.mota@ui1.es
}

\begin{abstract}
RESUMEN: La figura del matemático vasco Ricardo Vinós Santos es prácticamente desconocida en España, tanto para el gran público como para el más especializado. No ocurre lo mismo en México D.F., donde este científico, que se exilió allí tras la Guerra Civil española, goza de un especial prestigio por haber sido fundador de una de las instituciones educativas más emblemáticas del país azteca: la Academia Hispano-Mexicana. A lo largo de este artículo, se reconstruye aquellas etapas de su vida (infancia y juventud) que aún eran inéditas, incluso para su familia, y se aportan nuevos datos sobre su decidida implicación al servicio del Gobierno de la Segunda República durante la guerra y su labor educativa en el exilio.
\end{abstract}

Palabras clave: Exilio científico, Ricardo Vinós Santos, Segunda República, Guerra Civil, México.

\section{RICARDO VINÓS SANTOS: A SCIENTIST FROM VITORIA UNDER THE SERVICE OF THE SPANISH II REPUBLIC (1888-1959)}

ABSTRACT: The figure of the Basque mathematician Ricardo Vinós Santos is practically unknown in Spain, both for the general public and for the most specialized. The same does not happen in Mexico D.F., where this scientist,

1. Este artículo se ha realizado dentro del Grupo de Investigación GIR03. Humanidades y Ciencias sociales en la Era digital y Tecnológica de la Universidad Isabel I, en el marco de la línea de investigación L.05. Política, Economía, Sociedad y Memoria: El Estado en los siglos XIX a XXI de la que soy investigador responsable. 
who was exiled there after the Spanish Civil War, enjoys a special prestige for having been the founder of one of the most emblematic educational institutions of the Aztec country: The Academia Hispano-Mexicana. Throughout this article, it is reconstructed those stages of his life (childhood and youth) that were still unpublished, even for his family, and provide new information about his decisive involvement in the service of the Government of the Spanish Second Republic during the war and his educational work in exile.

Keywords: Scientific Exile, Ricardo Vinós Santos, Spanish Second Republic, Spanish Civil War, Mexico.

Recibido: 25 de julio de 2018 Aceptado: 8 de noviembre de 2018

\section{Introducción ${ }^{2}$}

El relato de algunos exiliados de la Guerra Civil, sobre todo el de los más destacados (políticos, escritores, artistas) convive en la memoria colectiva de nuestra sociedad. La guerra y el franquismo marcaron mucho a la generación de nuestros padres y abuelos, pues experimentaron en primera persona un régimen dictatorial que interrumpió el proceso democrático iniciado con la proclamación de la II República en $1931^{3}$. Para escapar de una lacerante dictadura, muchas personas optaron por exiliarse, tras comprobar que los militares sublevados estaban impulsando un "nuevo Estado" que fulminaba la legalidad republicana. Decidieron huir de un futuro incierto refugiándose en otros países, europeos y americanos, durante el tiempo en que la guerra estuvo activa, aunque, también, hubo otros que por temor a represalias lo hicieron una vez finalizada la contienda. Inicialmente, estos exiliados consideraron el asentamiento lejos de su hogar como una circunstancia provisional. Confiaban en que el ejército de la República hiciera frente a los golpistas o que las potencias democráticas occidentales les ayudaran a restaurar la democracia, como creyeron que ocurriría durante la II Guerra Mundial y en sus años inmediatamente posteriores ${ }^{4}$. Pero, pronto, fueron conscientes de que ese "breve" impasse se convertiría en

2. Quiero aprovechar este espacio para agradecer el interés por este trabajo al hijo de Ricardo Vinós, de nombre homónimo, y, especialmente, a su nieta, María Vinós, que me han proporcionado documentación inédita sobre su figura.

3. Casanova, J., República y Guerra Civil, Barcelona, 2007. Wagner, J., Las reformas más importantes de la Segunda República Española, Múnich, 2015.

4. Moradiellos, E., La perfidia de Albión: el gobierno británico y la guerra civil española, Madrid, 1996. Bosch, A., Miedo a la democracia. Estados Unidos ante la Segunda República y la guerra civil española, Barcelona, 2012. Avilés, J., "Francia y la guerra civil española. Los límites de una política", en Espacio, tiempo y forma. Serie V, Historia Contemporánea, no 5 , 1992, pp. 165-184. 
un proceso más duradero, un largo exilio del que los únicos culpables eran el enemigo franquista y, sobre todo, la indiferencia, la cobardía de las democracias y el contexto internacional.

Durante los casi cuarenta años de vida del franquismo, los exiliados del 36 experimentaron una dolorosa tensión que constantemente les situó entre la esperanza y la desilusión, la permanencia y el regreso, el recuerdo y el olvido $^{5}$. Mientras la dictadura del militar ferrolano estuvo activa, poco se supo de las actividades de los exiliados. No interesaba, era un tema tabú y no se les consideraba siquiera españoles ${ }^{6}$. Pertenecían a "otra España" que poco o nada tenía que ver con los valores militares, católicos, tradicionales y patrioteros que aquí se promocionaban y que eran ley divina ${ }^{7}$. Incluso, no importó que muchos de ellos estuvieran llevando a cabo notables avances en el campo científico. Y es que de los cientos de miles de personas (alrededor de 500.000, según los especialistas) que se exiliaron a Francia, Bélgica, Argentina, Uruguay, México y la Unión Soviética, más de un 1\% fueron intelectuales, profesores universitarios, científicos y escritores ${ }^{8}$. Dio lo mismo que para "el nuevo Estado" supusiera una auténtica fuga de cerebros de profesionales urbanitas de mediana edad y considerable prestigio en sus respectivas disciplinas, como se vio reflejado, por ejemplo, en el caso de México, donde el exilio científico republicano supuso cerca de un $6 \%$, porque, para el régimen, simplemente, no existían ${ }^{9}$. Junto a los 141 médicos y los 16 matemáticos que se exiliaron en la capital azteca, según datos del Servicio de Evacuación de Republicanos Españoles (SERE), cabe destacar a Ricardo Vinós Santos, un matemático alavés que tuvo un destacado papel en diferentes instituciones educativas de la Segunda República, como el Consejo Nacional de Cultura y la Junta de Cultura Española, y que desarrolló una gran labor científica y docente en México, donde fundó la Academia Hispano-Mexicana, una entidad formativa en diferentes niveles (secundaria y preparatoria), cuyo patronato contó con miem-

5. Alted, A. y Domergue, L. (coord.), El exilio republicano español en Toulouse, 19391999, Madrid, 2003, p. 22.

6. La cosificación de los republicanos se comprueba en la represión de posguerra, como se ha estudiado en Moreno Gómez, F., "La represión en la posguerra", en Juliá, S. et al.: Víctimas de la guerra civil, Madrid, 1999, p. 289.

7. Saz, Ismael, Fascismo y franquismo, Valencia, 2004. Preston, P., Las tres Españas del 36, Madrid, 2015. Juliá, S., Historias de las dos Españas, Madrid, 2010.

8. Peralta, J., "Sobre el exilio matemático de la guerra civil española (I)", en Suma: Revista sobre enseñanza y aprendizaje de las matemáticas, n 56, 2007, pp. 11-21; Id., "Sobre el exilio matemático de la guerra civil española (II)", Suma: Revista sobre enseñanza y aprendizaje de las matemáticas, n 57, 2008, pp. 9-22.

9. Ordoñez, M., "Científicos vascos del exilio español", en Garritz, A., Los vascos en las regiones de México, siglos XVI-XX, Tomo III, México, 1997, pp. 299-307. Respecto a la negación del otro, en este caso de los republicanos españoles, resulta interesante la reflexión que a este respecto se realiza en torno a la pobreza y la miseria en Del Molino, S., La España vacía. Viaje por un país que nunca fue, Madrid, pp. 101 y ss. 
bros del más alto nivel y prestigio: Josep Carner, Juan Roura y Carlos Obregón, entre otros ${ }^{10}$.

La figura de este científico vitoriano es completamente sorprendente. En absoluto se conoce a este personaje, al igual que tampoco suele ser habitual encontrar artículos y obras en las que se analice el papel que jugaron otros científicos alaveses que se mantuvieron fieles a la República tanto en la guerra como en el exilio. De hecho, para el caso de Vinós, el sondeo de las principales bases de datos y fuentes historiográficas especializadas tampoco ayuda, porque su figura es prácticamente anónima. Salvo artículos y capítulos de libro en los que se le cita de manera muy puntual, principalmente en obras de largo recorrido, sobre una temática muy concreta y publicadas fuera de España, la historia de este científico vitoriano ha pasado desapercibida incluso en su ciudad natal. De hecho, no se le cita en la Enciclopedia vasca Auñamendi, ni de manera anecdótica, y cuando se le menciona, como es el caso del diccionario biográfico español, que publicó la Real Academia de la Historia en 2009, apenas se le dedican cuatro líneas que se resumen de la siguiente manera: matemático alavés que desarrolló su actividad profesional en Madrid y que emigró a México donde fundó la Academia Hispano Mexicana. Este déficit se debe a que se sabe poco sobre su labor investigadora, docente, política y asistencial en España, pues los casi cuarenta años de dictadura franquista provocaron que sus logros y avances fueran omitidos, como ocurrió con muchos otros científicos e intelectuales que marcharon al exilio durante la Guerra Civil, entre ellos, el filósofo y traductor Eugenio Imaz, el arquitecto Roberto Fernández Balbuena y el también matemático Eugenio Álvarez Díaz ${ }^{11}$.

A lo largo de este texto, se arrojará algo más de luz sobre la historia de este matemático afincado por motivos laborales entre Logroño y Madrid y se intentará ir más allá de la aportación de simples datos telegráficos como los que hasta

10. De Llera, L., El último exilio español en América: grandeza y miseria de una formidable aventura, Madrid, 1996, p. 658. Pérez Galán, M., La Enseñanza en la Segunda República, Madrid, 2011, p. 300-324. Cifras sobre matemáticos y médicos en Ordoñez, M., El Comité Técnico de Ayuda a los Republicanos Españoles: historia y documentos, 1939-1940, México, 1997. Sobre el volumen de emigrados a México se deben confrontar los datos aportados en Lloréns, V., "La emigración republicana de 1939", en Abellán, J.L. (dir.), El exilio español de 1939, T.1, Madrid, 1976, pp. 126-127. Rubio, J., La emigración de la guerra civil de 1936-1939, Vol. I., Madrid, 1977, p. 180. Alted, A., La voz de los vencidos. El exilio republicano de 1939, Madrid, 2005, p. 222. El SERE y la Junta de Auxilio de los Republicanos Españoles, que crearían Juan Negrín e Indalecio Prieto, respectivamente, está analizado con cierto detalle en Plá, D., "1939", en Canal, J. (ed.), Exilios. Los éxodos políticos en la Historia de España, siglos XV-XX, Madrid, 2007, pp. 244-245 y ss. Romero, M., La oposición durante el franquismo. 3. El exilio republicano, Madrid, 2005. En cuanto a la etapa de Josep Carner en el exilio véase Subirana, J., Josep Carner: L'exili del mite (1945-1970), Barcelona, 2000.

11. Sobre Eugenio Imaz véase Ascunce, J.A., Topías y utopías de Eugenio Imaz. Historia de un exilio, Barcelona, 1991. 
el momento ha habido sobre él, reconstruyendo su vida a través de diferentes fuentes hemerográficas, bibliográficas y archivísticas. El objetivo es no sólo exponer que Ricardo Vinós se graduó en Ciencias Exactas en la Universidad Central de Madrid; que realizó estancias investigadoras en París, Roma y Berlín; que fue catedrático de la Escuela Industrial de Logroño, vocal de la Real Sociedad Matemática Española, tesorero-contador de la Sociedad Filarmónica riojana, jefe del Departamento técnico-gráfico de las Escuelas de Orientación Profesional de Madrid, presidente de la Junta Central de Formación Profesional de Madrid y vicepresidente de la Junta de Reorganización de la Enseñanza Secundaria y Profesional; sino también que fue un intelectual medianamente destacado en las reuniones de la sociedad liberal y la alta cultura española -principalmente madrileña- de los años 20 y 30. También se ofrecerán nuevos datos sobre los puestos de responsabilidad que ocupó en la organización política republicana, como el cargo de director del Departamento de Estadística que ocupó en la sección de evacuación de refugiados de la Junta de Defensa de Madrid, de vicepresidente en el Consejo Nacional de Cultura y de vocal en la Junta de Cultura Española del Gobierno Republicano.

En efecto, la figura de Ricardo Vinós Santos merece ser rescatada del olvido. Por eso, el principal objetivo de este artículo es ayudar a restablecer su memoria en el lugar que le corresponde en la historia del exilio, principalmente, porque, hasta el momento, su historia ha sido, sino negada y silenciada, al menos, olvidada por la historiografía. En definitiva, este trabajo aspira a que se abran nuevas investigaciones en torno a su figura, pagando parte de la deuda pendiente que tienen los historiadores con el profesor Vinós.

\section{Infancia y primeros años}

Hijo de Antonio Vinós y Ricarda Santos, el pequeño Ricardo nació en la vitoriana calle de la Herrería el 25 de junio de $1888^{12}$, en el seno de una familia católica de clase media, compuesta, junto a él, por cinco hermanos: Vicente, Antonio, Pepita y Juanita ${ }^{13}$. Políticamente, esta familia se movió en las pautas

12. Carta de naturalización como ciudadano mexicano $\mathrm{n}^{\circ} 1412$ a nombre de Ricardo Vinós Santos, Archivo familiar Vinós y Archivo General de la Nación, Departamento del Distrito Federal de México, Exp. VII/521.2(46)/V-5-6, 15-10-1940. En otras fuentes se señala que nació el 29 de junio de 1887. Cfr. Llombart, J., "Matemáticos españoles del exilio. Notas biográfico científicas correspondientes a los años previos a la guerra civil", en Sánchez, G. y García de León, P., Los científicos del exilio español en México, Michoacán, 2001, pp. 201-234.

13. Tradicionalmente, Álava ha sido profundamente conservadora y durante el periodo en que nació nuestro protagonista lo era especialmente, aunque ello no se viera reflejado en el Ayuntamiento de Vitoria, pues los partidos del turno tuvieron que pactar en numerosas ocasiones con partidos dinásticos y extradinásticos. Una provincia gobernada por los Urquijo, una familia caciquil con gran poder de influencia sobre toda la región desde su distrito del 
del tradicionalismo, primero, cercana al carlismo y, conforme sus hermanos fueron creciendo y entrando en política, afín al nacionalismo vasco, aunque como se verá más adelante no fue la inclinación ideológica de Ricardo ${ }^{14}$. Económicamente bien posicionada, con cierta holgura incluso, pues el padre de los Vinós ocupaba un puesto destacado en la Junta Directiva de la Cámara de Comercio e Industria de Álava, de la cuál era tesorero, aparte de otros negocios vinculados al comercio ${ }^{15}$. En definitiva, al igual que los Ortíz, Lengarán, Ortíz de Urbina, Fernández de Retana, Sautu, Buesa y Ruíz de Eguílaz, una familia bien situada socialmente, en parte, gracias a la política municipal y a los lugares preeminentes que ocuparon (y ocuparían) en la derecha local durante toda la Restauración ${ }^{16}$.

Respecto a los estudios, cabe señalar que desde las primeras etapas escolares se interesó por la Ciencia, aunque fue durante su periodo como estudiante en el Instituto de Segunda Enseñanza de Vitoria cuando ese interés se reflejó en resultados tangibles, más allá, incluso, de los relacionados con lo meramente científico. Así, fue un alumno notable en idiomas, Historia y Geografía y sobresaliente en Literatura y Psicología y Lógica ${ }^{17}$. Sus buenas calificaciones en esta última materia le hicieron que se decantara por estudiar la carrera de Matemáticas, sección Exactas, en la Universidad Central de Madrid entre 1903 y 1910. Muy pronto demostró sus aptitudes, obteniendo sobresalientes con matrícula de honor en Física general y Mecánica racional, sobresaliente en Astronomía esférica y Geodesia y en Complementos de Cálculo infinitesimal, notable en

valle de Ayala. Rivera A., y De Pablo, S., Profetas del pasado. Las derechas en Álava, VitoriaGasteiz, 2014, pp. 128-138 y ss. Sanz Legaristi, P. y Rivera, A., "Las elecciones al Ayuntamiento vitoriano durante la Restauración", en Vasconia: cuadernos de sección Historia y Geografía, ${ }^{\circ}$ 8, 1986, pp. 117-134.

14. De hecho, Antonio Vinós fue miembro de Eusko Gastedi Batza, las juventudes del PNV, en 1919, y, posteriormente, concejal por este partido y por una de las escisiones del mismo: Comunión Nacionalista Vasca. Incluso, fue presidente del Araba Buru Batzar. También su hermano Vicente Vinós fue concejal durante estos años por el PNV. Rivera y De Pablo, Profetas del pasado, op. cit., pp. 310-312. Ruíz, G., Álava, una provincia en pie de guerra. Voluntariado y movilización durante la Guerra Civil, Bilbao, 2016, pp. 166-167. Enciclopedia General Ilustrada del País Vasco Auñamendi, vol. LII, p. 369.

15. Memoria presentada por la Junta Directiva de la Cámara de Comercio de Álava a la asamblea general, 30-12-1906, Archivo del Territorio Histórico de Álava (ATHA), sig. ATHAADH-FCHSA-021-027.

16. Rivera y De Pablo, Profetas del pasado, op. cit., pp. 322-323. Tal fue su fijación por estar en la política local que, incluso, ante la instauración de la dictadura de Primo de Rivera en 1923, Antonio Vinós aparcó su credo nacionalista para evitar problemas. No obstante, también se ve más adelante que Vicente Vinós ocupó cargos de concejal del cual se le ve renunciando en 1929. Expediente $\mathrm{n}^{\circ} 74$ por que Vicente Vinós renuncia a su cargo de concejal, 17-4-1929, Vitoria, Archivo Municipal de Vitoria, LI/017/069. Véase también Gómez Calvo, J., Matar, purgar, sanar. La represión franquista en Álava, Madrid, 2014, pp. 118-119.

17. "Cuadro de Honor", La Libertad, 5-6-1901, p. 1. "Cuadro de Honor", La Libertad, 30-5-1903, p. 1. 
Química General y en Cosmografía y Física del Globo, y de aprobado en el resto de asignaturas que cursó durante la carrera ${ }^{18}$.

Finalizada la licenciatura, en mayo de 1911, Vinós, al igual que harían sus hermanos, intentó entrar en la política municipal, pero, debido al incumplimiento del requisito de "residencia durante dos años" su solicitud para ser incluido en el censo electoral fue desestimada, por lo que no pudo formar parte de las listas electorales ${ }^{19}$. Tuvo la opción de apelar ante la Audiencia Territorial de Burgos, pero, por el momento, las fuentes consultadas disponibles no permiten afirmar o negar que así lo hiciera. Probablemente desistiera para dedicarse en cuerpo y alma a la docencia, ya que en noviembre de 1911 consiguió -por oposición- la plaza de ayudante de la Sección de Ciencias del Instituto General y Técnico de Vitoria, que dirigía Federico Baráibar ${ }^{20}$. Esta vocación docente, pero, sobre todo, sus aspiraciones, le llevaron en mayo de 1913 a optar a un puesto de profesor en el reconocido colegio de $1^{\mathrm{a}}$ y $2^{\mathrm{a}}$ Enseñanza de San Antonio de Padua de Logroño, en donde, previa obtención de la plaza de profesor de término en la Escuela de Artes y Oficios, impartió las asignaturas de Aritmética, Geometría, Matemáticas, Geometría Plana y del Espacio, y Trigonometría y Topografía ${ }^{21}$.

Sus éxitos profesionales y progresiva notoriedad social, sumado a la fama que ya tenía su familia en la capital alavesa, ayudaron a que Vinós se convirtiera en una celebridad local, digno, incluso, de que sus actividades sociales fueran recogidas en la prensa local alavesa y riojana ${ }^{22}$. También ayudó el hecho de que se supiera mover muy bien entre los medios político-culturales de la época, como se demuestra a través de su presencia en destacados eventos solemnes, como el que se recoge a en la siguiente noticia extractada del diario La Rioja ${ }^{23}$ :

18. Ricardo Vinós Santos, Archivo Histórico Nacional (AHN), Sig. Universidades, 6284, Exp. 6. Véase también Archivo General de la Administración (AGA), leg. 1555-31, citado en Llombart, "Matemáticos españoles del exilio", pp. 201-234.

19. "Censo electoral", La Libertad, 19-5-1911, p. 1.

20. "Historial académico-curricular de Ricardo Vinós Santos (1911-1932)", elaborado por Elena Cruz-López (su esposa), Archivo familiar Vinós, sin fecha.

21. Registro de títulos y credenciales, Archivo Histórico Provincial de La Rioja, Fondo Escuela de Artes y Oficios, sig. EAD-125/3, p. 11. Agradezco a la directora del archivo, Micaela Pérez Sáenz, toda la ayuda proporcionada en la localización de este documento. Véase también La Rioja, 25-6-1916, p. 4.

22. El diario La Libertad solía informar de las idas y venidas a y de Logroño de Ricardo Vinós, poniéndolo multitud de etiquetas como "afamado profesor", "el bueno", etc. Véase La Libertad, 16-12-1913, p. 2 y La Libertad, 14-4-1914, p. 2.

23. Sobre la ciudad de Logroño y su provincia véase Bermejo Martín, Francisco. La Rioja contemporánea 1784-1996, Logroño 2013. Sesma Muñoz, José Ángel (et al.). Historia de la ciudad de Logroño. Logroño, 1996. Cerrillo Rubio, M.I. La formación de la ciudad contemporánea. Logroño entre 1850 y 1936, Logroño, 1993. Climent López, E. El proceso de industrialización de La Rioja. Logroño, 1992. AA.VV. Historia de La Rioja, Logroño, 1983. García Prado, Justiniano. Historia de la Rioja, Logroño, 1983. 
Fue conducido ayer tarde al Cementerio el cadáver del rico farmacéutico bilbaíno don Juan Bautista Galdiz, que llevaba aquí una temporada buscando la salud perdida. El lujoso féretro iba en elegante carroza-estufa, tirada por cuatro caballos servidos a la Federica, y llevaban las cintas don Hilario O. de Lanzagorta, don Ricardo Vinós, don Eduardo Amalric y don Félix Gómez Escolar. Presidieron el duelo dos hijos del finado. A su distinguida familia renovamos nuestro pésame ${ }^{24}$.

Una notoriedad que quedó más clara, si cabe, en el momento en que Vinós entró a formar parte de la candidatura a la presidencia de la Filarmónica de Logroño que encabezaba Joaquín Elizalde, catedrático de instituto y futuro alcalde de Logroño (1926-1930). Una lista compuesta, además, por ilustres riojanos como Saturnino Aragón (presidente del club de fútbol Sport Club), Fermín Maguregui (músico), Santiago García Baquero (futuro senador por la entonces provincia de Logroño entre 1918 y 1923), Agustín Cadarso (arquitecto y diseñador del Ateneo riojano) e Isaac Guadan (bibliotecario y vicesecretario del Instituto provincial de Logroño) ${ }^{25}$. Por su cercanía a estas personalidades, algunas políticamente de signo liberal sagastino -actitud preponderante en la capital riojana-, durante su estancia en Logroño, ocupó la presidencia de varias mesas electorales en diferentes ocasiones ${ }^{26}$. Una designación que como fue habitual durante la Restauración respondió a un sorteo cooptativo realizado entre los miembros del ayuntamiento y personalidades cercanas al poder local, con la finalidad de "controlar" el resultado electoral ofreciendo una imagen de democracia libera ${ }^{27}$.

Su buena reputación le volvió a colocar en el punto de mira de la prensa local alavesa, destacándose su asistencia en abril de 1917 al enlace matrimonial entre su hermano Antonio y Patrocinio Aldama en el santuario de Estíbaliz; y riojana, al aparecer, en octubre de 1919, como un personaje destacado en el funeral de Sotero Irasarri, archivero de hacienda, conservador del museo provincial de Logroño, bibliotecario en el Instituto General y Técnico y hermano político del alavés Herminio Madinaveitia, catedrático del mencionado instituto riojano ${ }^{28}$.

24. La Rioja, 30-1-1915, p. 2.

25. "La Filarmónica", La Rioja, 8-2-1915, p. 2. Ricardo Vinós comenzaría siendo contador y pasaría a ocupar el cargo de secretario a principios de 1916, La Rioja, 3-2-1916, p. 2. Agradezco a Sergio Cañas la colaboración que me ha prestado para identificar a estas personalidades. Asimismo, la gran parte de la información ha sido contrastada con la web especializada en historia de La Rioja http://www.bermemar.com.

26. La Rioja, 7-11-1915, p. 2. La Rioja, 30-1-1920, p. 5. y La Rioja, 15-4-1923, p. 2.

27. Respecto al funcionamiento electoral en la provincia de La Rioja durante la Restauración y el caciquismo, véase Delgado Idarreta, J.M., "La Rioja", en Varela Ortega, J., (dir.): EI poder de la influencia. Geografía del caciquismo en España (1875-1923), Madrid, 2001, pp. 497-514. Varela Ortega, J., Los amigos políticos. Partidos, elecciones y caciquismo en la Restauración (1875-1900), Madrid, 2001.

28. "La boda de ayer. Vinós=Aldama", El Heraldo Alavés, 30-4-1917, p. 3. "Don Sotero Irasarri", La Rioja, 15-10-1919, p. 2. (copia en La Libertad, 15-10-1919, p. 2). Sobre Sotero Irasa- 
El prestigio de Vinós fue aumentando no sólo socialmente, sino también profesional y económicamente. Si en 1913, cuando se trasladó a Logroño, comenzó recibiendo el modesto sueldo de 3.000 pesetas con una categoría de profesor media-baja, en 1919, se comprueba que asciende en el escalafón funcionarial (llegando a ser catedrático), situándose entre los números 122 y 160, que recibían el salario de 6.500 pesetas $^{29}$. A partir de aquí, las fuentes disponibles para la etapa 1919-1924 escasean, detectándose un importante vacío en la documentación. $\mathrm{Ni}$ en las hemerotecas, ni en los archivos consultados hay referencia alguna a Vinós durante ese periodo, únicamente hay referencias indirectas procedentes del estudio de Luis Español sobre la Real Sociedad Matemática Española, quien menciona que Vinós fue un miembro destacado de esta institución durante estos años en Logroño ${ }^{30}$.

Sin embargo, durante los años mencionados, se sabe que se produjo un hecho fundamental para la trayectoria profesional de Vinós. Este trabajaba dentro de la sección de formación profesional del mencionado instituto riojano, que hacía las veces de Escuela Industrial de Artes y Oficios. Así, cuando en 1924 las Escuelas Industriales pasaron a depender del Ministerio de Trabajo, Industria y Comercio, separándose de las de Artes y Oficios, que continuaron vinculadas al Ministerio de Instrucción Pública y Bellas Artes, el matemático alavés continuó adscrito a la plantilla de profesorado de este último ministe$r^{r i{ }^{31}}$. Fruto de este cambio de dirección en las Escuelas Técnicas y en virtud, se entiende, del rendimiento de Vinós al frente de sus funciones, el citado ministerio dispuso "que para adaptar el actual profesorado numerario a las secciones que figuran en los mencionados capítulos y artículo sean ascendidos [...]: a la sección quinta del escalafón con el sueldo anual de 9.000 pesetas, D. Ricardo Vinós y Santos" ${ }^{\prime 32}$. Poco tiempo después de este ascenso, solicitó una ayuda para realizar una estancia de especialización investigadora en París

rri, Sánchez Trujillano, M.T., "El coleccionismo público. Condicionantes jurídicos y objetivos. El Museo de La Rioja", en Berceo, $\mathrm{n}^{\circ}$ 161, p. 128. Toldrà, J., José María Escrivá en Logroño (1915-1925), Madrid, 2007, p. 232.

29. La Rioja, 30-10-1919, p. 3.

30. Español, L., "Presencia de matemáticos en La Rioja como socios de la Real Sociedad Matemática Española durante el periodo 1911-1960", en Zubía: revista de ciencias, 33-34, pp. $12-17$.

31. Real Decreto (RD) 15-3-1924, citado en Núñez Izquierdo, S., El arquitecto Francisco Gil Conzález (1905-1962) y la arquitectura salmantina del segundo tercio del siglo XX, Salamanca, 2014, p. 689. Gaceta de Madrid, no 292, 19-10-1926, p. 354. Historial académicocurricular de Ricardo Vinós Santos (1911-1932)", elaborado por Elena Cruz-López (su esposa), Archivo familiar Vinós, sin fecha. Martínez Navas, I., "La Escuela Industrial y de Artes y Oficios de Logroño", en REDUR II, 2013, pp. 73-106. No obstante, las informaciones de Vinós son confusas porque tras la separación de las mencionadas escuelas, a veces, aparece vinculado al ministerio de instrucción pública y otras se le denomina profesor de la Escuela de Comercio de Logroño. La Libertad, 11-2-1929, p. 1.

32. Gaceta de Madrid, nº 194, 13-7-1926, p. 289. 
y Roma, donde estudió "Geometría algebraica, con la retribución diaria de 29,16 pesetas, el primer mes; la de 24,16 el último y la de 14,16, los días restantes" ${ }^{\prime 33}$. Estuvo en Francia e Italia durante 8 meses, de manera escalonada, entre los años 1925 y 1927, y aunque fue poco tiempo, a su regreso, algunas cosas cambiaron de manera decisiva ${ }^{34}$.

Como consecuencia del nuevo Estatuto de Enseñanza Industrial de 1924, que había dado lugar a la división en dos de la Escuela Industrial y de Artes y Oficios, y de la aprobación del Estatuto de Formación Profesional de 1928, se asentó un proyecto educativo basado en nuevas pautas de orientación social y pedagógica impuestas por la dictadura de Primo de Rivera; es decir, se impulsó un proyecto que aspiró a centralizar toda la formación profesional industrial bajo el Ministerio de Trabajo, Comercio e Industria y que buscó evitar que esta enseñanza continuara gobernada por iniciativas particulares y privadas que no daban al país los beneficios sociales y económicos que el régimen esperaba ${ }^{35}$. La reestructuración que realizó la dictadura primorriverista con este tipo de formación influyó en la carrera de Vinós e introdujo ciertas modificaciones. Por de pronto, su puesto funcionarial pasó a depender en exclusiva del Ministerio de Trabajo y las asignaturas que debía impartir en la Escuela Industrial de Logroño, dejando un margen prácticamente nulo para la libertad de cátedra; las directrices de la dictadura en este último aspecto eran muy explícitas: que no existiera diferencia alguna entre un maestro de taller/fabricación y un profesional/jefe técnico ${ }^{36}$. Aun así, el científico vitoriano continuó en la brecha. Quizá en unas condiciones de trabajo mejorables, pero seguía presente en la primera línea riojana, alavesa y, como se verá, española.

33. Gaceta de Madrid, no 292, 19-10-1926, p. 354. Su estancia en Roma se señala en Lines, A., "La matemática en la Rioja en el primer tercio del siglo XX y años de su entorno", en Zubía, 15, 1997, pp. 121-129.

34. Historial académico-curricular de Ricardo Vinós Santos (1911-1932)", elaborado por Elena Cruz-López (su esposa), Archivo familiar Vinós, sin fecha.

35. Rico Gómez, M.L., "La enseñanza profesional y las clases medias técnicas en España (1924-1931)", en Hispania, vol. LVVII, 240, 2012, p. 125.

36. De Madariaga, C., La formación profesional de los trabajadores, Madrid, 1933, p. 227. Se señalaba respecto a las asignaturas a impartir por Vinós lo siguiente en la Gaceta de Madrid: "Ilmo. Sr.: visto el acoplamiento del profesorado de la Escuela Industrial de Logroño a los nuevos grupos de asignaturas establecidos en el Estatuto de Formación Profesional de 21 de diciembre próximo-pasado: considerando que la propuesta que se formula se ajusta a las prescripciones de los artículos 16 y 18 del citado texto legal, S.M. El rey (q.D.g.) ha tenido a bien disponer lo siguiente: $1^{\circ}$ Que sean nombrados para los grupos que se mencionan los siguientes profesores numerarios D. Ricardo Vinós Santos (ampliación de Matemáticas). D. Onofre Gregorio Mendiola Ruíz (Ciencias físico-químicas) [...] $2^{\circ}$ Que de acuerdo con lo previsto en el artículo 18 de nombre a D. Florencio Martínez del Pueyo, profesor auxiliar del grupo de ampliación de matemáticas. De real orden lo digo a V.E. Para su conocimiento y efectos. Dios guarde a V.E. Muchos años. Madrid 21 de junio de 1929, AUNOS, señor director general de Previsión y corporaciones". Gaceta de Madrid, n 185, 4-7-1929, n 924, pp. 98-99. 
No hay duda de que su estancia en el extranjero ayudó a que su popularidad aumentara en los espacios intelectuales y políticos. Como se ha señalado en algunas investigaciones y ha afirmado su familia, fue una persona con vínculos muy estrechos con la cultura madrileña de base progresista, en la que, primero, participó de manera decisiva para ayudar a instaurar el régimen democrático republicano y, posteriormente, ocupó un papel destacado en el ámbito educativo $^{37}$. De hecho, esta implicación y su vocación docente ya se vio en los años finales de la dictadura de Primo de Rivera. Finalizada la Guerra de Marruecos (1909-1927), participó en diferentes lecturas y conferencias del Instituto de reeducación profesional de inválidos, una institución a la que a día de hoy se considera precursora de la orientación profesional, que se dedicó a readaptar funcional y psicológicamente a muchos veteranos de guerra ${ }^{38}$. En efecto, fue uno de los impulsores de esta reeducación y, como tal, ofreció una lección magistral que quedó recogida en el diario $A B C$ de la siguiente manera:

El sábado se celebró en el instituto de reeducación profesional una interesante sesión cultural para obreros. [...] D. Ricardo Vinós dio una conferencia sobre el tema "Taylor y la organización científica del trabajo", exponiendo a grandes rasgos la obra del gran ingeniero norteamericano, encaminada a aumentar el rendimiento del trabajo industrial por medio de la eliminación del despilfarro, conseguido gracias al estudio experimental de los diversos trabajos. El Sr. Vinós salió al paso de algunas críticas de Taylor, que encuentran en su obra una preocupación esencialmente materialista, contestando que Taylor fue también hombre de corazón, que se interesó de una manera marcada por el bienestar de los obreros ${ }^{39}$

Apenas un mes más tarde, Vinós fue ascendido a la sección $4^{\mathrm{a}}$ del escalafón de profesores numerarios ${ }^{40}$.

\section{II República y Guerra Civil}

La proclamación de la II República el 14 de abril de 1931, vino acompañada lógicamente de un nuevo régimen. Un sistema democrático que trajo nuevos ai-

37. Es posible que fuera recibido en la Corte, a no ser que el periódico del que se ha extraído esta información utilice Corte como sinónimo de Madrid y capital de España. La Libertad, 26-12-1930, p. 1.

38. Monteagudo, M.J. y Chisvert, M., "Los inicios de la psicotecnia en España: el trabajo del Instituto de Reeducación de inválidos del trabajo de Carabanchel (1922-1929)", en Revista de Historia de la Psicología, vol. 28, n 2/3, 2007, pp. 189-196.

39. "Informaciones y noticias de lecturas y conferencias, en el Instituto de reeducación profesional", $A B C, 12-11-1929$, p. 25.

40. Historial académico-curricular de Ricardo Vinós Santos (1911-1932)", elaborado por Elena Cruz-López (su esposa), Archivo familiar Vinós, sin fecha. 
res y, sobre todo, muchos cambios para el ámbito político y educativo ${ }^{41}$. A la luz de las fuentes consultadas, parece ser que el trabajo realizado por Vinós en la Escuela Industrial de Logroño estuvo altamente valorado por las diferentes instancias de Madrid, primero, por el Consejo de Instrucción Pública y, ya entrada la II República, por el Consejo Nacional de Cultura ${ }^{42}$. De hecho, en diferentes concursos públicos fue presidente del Tribunal de Oposiciones de Dibujo Lineal de las Escuelas de Artes y Oficios de Almería, Barcelona, Palencia, Valladolid, Sevilla y Soria, y el mencionado Consejo le expresó gratitud por su trabajo en diferentes ocasiones ${ }^{43}$.

Al calor del despliegue del nuevo régimen se fueron produciendo diferentes cambios en la trayectoria de Vinós. En 1932, se estableció en Madrid, concretamente en la calle Velázquez $71^{44}$, para poner en marcha diferentes proyectos educativos de carácter público, entre ellos, la Escuela de Orientación Profesional, aprovechando la importancia que cobraron organismos de renovación pedagógica como la Institución Libre de Enseñanza (en funcionamiento desde el último tercio del siglo XIX) que creían que el Estado debía intervenir para ayudar al desarrollo social y democrático de la nación ${ }^{45}$. En mayo de 1933, el trabajo de Vinós y su implicación en nuevos modelos educativos se tradujo en su nombramiento como vocal de la sección segunda del Consejo Nacional de Cultura. Así, informó La Vanguardia de esta designación:

[...] ha nombrado presidente del Consejo nacional de Cultura a don Teófilo Hernando y Ortega, y vocales a los señores siguientes: Con destino a la sección primera, a don Pablo Cortés Faure, profesor de Escuela Normal, en la vacante producida por renuncia de don Lorenzo Luzuriaga Medina; a don Vicente Valls Ánglés, inspector de primera enseñanza, en la vacante por renuncia de don Fernando Sainz Ruiz, y a don Ernesto Winter Blanco, ingeniero, en la vacante producida por fallecimiento de don Manuel Ainaud y Sánchez. Con destino a la sección segunda; a don Ricardo Vinos y Santos, profesor de Escuela Superior de Trabajo ${ }^{46}$.

41. Herrero, C., "Nota sobre la educación en la Segunda República Española", Didácticas Específicas, n 13, 2015, pp. 186-191. Caballero, Á., "La educación en la Segunda República (1931-1937)", en Vico, M. (coord.), Educación y cultura en la Málaga contemporánea, Málaga, 1995, pp. 135-164. París, C., "Educación y cultura en la Segunda República", en Rodríguez, J., La República y la cultura. Paz, guerra y exilio, Madrid, 2009, pp. 253-260.

42. Mayoral, V., "El Consejo Nacional de Educación: origen y transformaciones", en $R e-$ vista de Educación, no 240, 9, 1975, pp. 127-140.

43. Carta dirigida por el Consejo Nacional de Cultura a Ricardo Vinós, Madrid, 4-111932, Archivo familiar Vinós.

44. Fuentes familiares señalan que la calle era Velázquez 73.

45. Español, "Presencia de Matemáticos", op. cit., p. 17. Respecto a la Institución Libre de Enseñanza, una interesante reflexión en Del Molino, La España vacía, op. cit., p. 116 y 133-139.

46. La Vanguardia, 30-5-1933, p. 26. Pero, a la par que ascendía profesionalmente lo continuaba haciendo socialmente, como lo demuestra el hecho de que $A B C$ se hiciera eco de una 
Su afán por mejorar el sistema educativo en el ámbito de la formación profesional se vio finalmente cumplido, cuando en octubre de 1933, después de mucho esfuerzo y largas horas de trabajo, fue inaugurada la Escuela de Orientación Profesional de Chamartín de la Rosa:

El edificio es magnífico y tiene modernas instalaciones. Cuenta con tres talleres de forja ajuste y carpintería; una amplia clase de dibujo y dos más para las enseñanzas orales. Asistieron el subsecretario de Instrucción Pública, Sr. Bolívar; el director de Enseñanza Técnica Sr. Cebada; D. Federico de Lafuente; el presidente Formación Profesional de Madrid, Sr. Almiñaque; El alcalde de Chamartín de la Rosa, el jefe del Departamento técnico-gráfico de las Escuelas de Orientación Profesional, D. Ricardo Vinós; el jefe del Departamento de talleres Sr. Krahe; el concejal D. Francisco Cantos, el Sr. Moreno Caracciolo y otras distinguidas personalidades. Pronunciaron discursos los Sres. Vinós, Lafuente, Almiñaque y Cantos. Todos elogiaron esta clase de escuelas y prometieron su apoyo y desenvolvimiento. Por último, el Sr. Bolívar declaró la escuela inaugurada en nombre del Gobierno ${ }^{47}$

Sus puestos de responsabilidad iban en ascenso. Al constituirse en diciembre de 1933 el comité del Congreso Internacional de Enseñanza Técnica, que se celebró en Barcelona en mayo de 1934 al amparo del Bureau International de L'Enseignement Technique parisino (una organización cuyo objetivo era repensar la formación de los futuros trabajadores) y en el que se debatieron las nuevas propuestas metodológicas sobre la formación profesional, el ministerio de Instrucción Pública decidió nombrar delegados del Consejo Nacional de Cultura ante esta institución a Ricardo Vinós, Ernesto Winter y Manuel Álvarez ${ }^{48}$; síntoma de que confiaban en el buen criterio del profesor Vinós, quien tuvo que rendir cuentas sobre la organización de este Congreso y relaciones con el Bureau ante el presidente de la República, Niceto Alcalá Zamora ${ }^{49}$.

No fue la única institución en realizar un movimiento en tal sentido, pues el día 19 de este mismo mes fue elegido vocal del patronato local de la Forma-

boda entre Carmen Sánchez Bordona y el ingeniero industrial Fernando Montes y destacara que Ricardo Vinós era uno de los testigos por parte de la novia. "Ecos diversos de sociedad", $A B C$, 3-6-1932, p. 19. Cfr. Consejo Nacional de Cultura, CDMH, PS-Madrid, Caja 455, Leg. $4001, \mathrm{n}^{\circ} 135$, fol. $66-68$.

47. "Inauguración de la Escuela de Orientación Profesional de Chamartín de la Rosa", $A B C, 18-10-1933$, p. 33.

48. La Vanguardia, 17-12-1933, p. 25. El Bureau International de L'Enseignement Technique ha sido ampliamente estudiado en Matasci, Damiano: "L'education, terrain d'action internationale: le Bureau International de l'enseignement technique dans les années 1930", Relations Internationales, 151, 3, 2012, pp. 37-48.

49. "Audiencia del presidente", La Vanguardia, 4-3-1934, p. 24. 
ción Profesional de Madrid, a propuesta formulada por la Dirección General de Enseñanza Profesional y Técnica ${ }^{50}$. Asimismo, en abril de 1934, fue designado vocal de las misiones pedagógicas de la Institución Libre de Enseñanza, en sustitución del extremeño Juan Uña, como queda reflejado en La Gaceta de Madrid:

Presidencia del Consejo de Ministros. Orden. Ilmo. Sr.: A propuesta del Ministerio de Instrucción Pública y de acuerdo con lo establecido en el artículo $3^{\circ}$ del Decreto del 29 de diciembre de 1933 y en el de 19 de enero del año actual. Esta presidencia ha tenido a bien nombrar vocal de este patronato en representación del Consejo Nacional de Cultura, a D. Ricardo Vinós y Santos, en la vacante por renuncia de don Juan Uña, que anteriormente lo desempeñaba. Lo digo a V.I. Para su conocimiento y efectos oportunos. Madrid. 4 de abril de 1934. Alejandro Lerroux, Sr. presidente del Patronato Administrador de los bienes incautados a la Compañía de Jesús ${ }^{51}$.

Si Vinós quería entregarse a su puesto en la Institución Libre de Enseñanza debía tener su sede de trabajo en Madrid. Así que Ramón Prieto, director general de Enseñanza Profesional y Técnica y cercano a la Institución Libre de Enseñanza, movió hilos, y, apenas unos días más tarde a este nombramiento, confirmó su traslado definitivo a la capital de España, ocupando una "plaza de profesor numerario del grupo tercero vacante en la Escuela Superior de Trabajo de Madrid"52. Entre 1934 y 1935, su protagonismo fue creciendo en la capital política española: presidente de los tribunales de oposición a cátedra de Institutos Nacionales, asiduo de eventos de la sociedad liberal madrileña y artífice del proyecto de reglamento para las Escuelas Superiores de Pintura, Escultura y Grabado $^{53}$; incluso renunció a un ascenso dentro del Consejo Nacional de Cultural por priorizar su compromiso para la reorganización de los centros de For-

50. Gaceta de Madrid, no 353, 19-12-1933, p. 1955.

51. Gaceta de Madrid, $n^{\circ}$ 97, 7-4-1934, p. 150. Sobre la labor de Juan Uña y la Institución Libre de Enseñanza: Canes, F., "Las misiones pedagógicas: educación y tiempo libre en la Segunda República", en Revista Complutense de Educación, vol. 4, n 1, 1993, p. 148 y ss.

52. Gaceta de Madrid, $\mathrm{n}^{\circ}$ 100, 10-4-1934, p. 206.

53. Gaceta de Madrid, $n^{\circ}$ 214, 28-4-1934, p. 642. Gaceta de Madrid, $n^{\circ}$ 295, 22-10-1934, p. 581. Carta dirigida por el Consejo Nacional de Cultura a Ricardo Vinós, Madrid, 26-4-1935, Archivo familiar Vinós. El profesor alavés asistió a numerosos eventos y homenajes, como queda recogido en $A B C$ (20-12-1934, p. 45): Homenaje al arquitecto D. Luis Moya: Se nos ruega la inserción de esta nota: Acaba de concedérsele al arquitecto don Luis Moya el Premio Nacional de Arquitectura, que con otros recientes premios culmina una serie de éxitos. Y queriendo dar ocasión un grupo de amigos y admiradores a testimoniarle su afecto y admiración, organizan un homenaje cuya comisión la forman los señores siguientes: Adolfo Blanco, Pío del Río, [...] Juan de la Encina, [...] Álvarez Ossorio [...], Juan Cristóbal, Ricardo Vinós [...]. Las tarjetas para el homenaje que se celebrará hoy, a las diez de la noche, pueden recogerse en el hotel París, donde ha de celebrarse, y en el Círculo de Bellas Artes. 
mación Profesional Obrera ${ }^{54}$. La renuncia, empero, no impidió que, meses más tarde, fuera ascendido a vicepresidente del Consejo Nacional de Cultura, un cargo que le sirvió para tener una mayor presencia, si cabe, en diferentes juntas, comités y tribunales dedicados a la mejora de la enseñanza profesional, a la par que mantuvo su puesto de director del centro de orientación profesional de la Escuela de Preparatoria y Orientación Profesional del barrio de Embajadores ${ }^{55}$.

En abril de 1936, una vez más, fue recibido por el presidente de la República, junto a otras personalidades como José Alonso Mallol, director general de seguridad, Domingo Zarazúa, vicepresidente del Jurado Mixto de la Alimentación, Manuel Acal, jefe del personal del ministerio del Estado, el periodista Luis Massip o el militar Hermenegildo Nieto Roldán ${ }^{56}$. De este modo, iniciada la sublevación militar de Sanjurjo, Mola y Franco, Ricardo Vinós era parte importante en el ámbito educativo dentro de la estructura del Gobierno republicano en Madrid, como prueba el hecho de que en agosto de 1936 fuera definido en la Gaceta de Madrid como "vicepresidente de la Junta de Enseñanza Profesional del Ministerio de Bellas Artes e Instrucción Pública y de la Junta de Segunda Enseñanza" ${ }^{57}$.

Pero, tras el fallido golpe de Estado, su compromiso fue más allá. La sublevación militar produjo que Francisco Largo Caballero, presidente del gobierno de la República, tomara medidas para mantener la capital de España a toda costa. Para ello creó la Junta de Defensa de Madrid (JDM) en septiembre de 1936, un organismo liderado por él mismo que integraba las distintas facciones del Frente Popular y que fue dirigido por el general Miaja a partir de noviembre hasta su autodisolución en abril de 1937. Antes de la mencionada reestructuración de noviembre, diferentes organismos y personalidades afines a la República se organizaron para preparar la evacuación y realizar diferentes labores asistenciales que ayudaran al traslado del Gobierno Republicano a Valencia. En ese primer momento, Ricardo Vinós colaboró en la organización de la evacuación, pero, fue, a partir de la entrada de Miaja, cuando lo hizo de manera determinante. La Consejería de Evacuación, diseñada en cuatro secciones (secretaría general, estadística, negociado general de evacuaciones y evacuación interior) se asignó al representante de Unión Republicana, Enrique Jiménez, que fue instalada en el palacio del marqués de Cortina, contando con empleados para todas las dependencias. Ricardo Vinós, estuvo al frente del departamento de Estadística de Evacuación, junto a Orencio Muñoz e Ignacio Jiménez, que ayudaron a que, a partir del 7 de diciembre de 1936, se impusiera un mayor control sobre el sistema de evacuación para favorecer y disciplinar los traslados, coordinar las

54. Gaceta de Madrid, $\mathrm{n}^{\circ} 284,11-10-1935$, p. 227.

55. Gaceta de Madrid, no 94, 3-4-1936, p. 98. ABC, 4-4-1936, p. 38. El Liberal, 5-4-1936, p. 2. Noticiero Bilbaíno, 19-4-1936, p. 5. Gaceta de Madrid, nº 116, 25-4-1936, p. 743.

56. "Notas políticas", La Vanguardia, 29-4-1936, p. 36.

57. Gaceta de Madrid, n 236, 23-8-1936, p. 1429. 
iniciativas, informar a las familias de los evacuados y realizar las salidas en las mejores condiciones ${ }^{58}$.

Una vez disuelta la JDM, Ricardo Vinós se trasladó a Valencia a mediados de 1937 y de allí, poco tiempo después, a Barcelona. En el transcurso de todos estos acontecimientos, Ricardo Vinós contrajo matrimonio con Elena Cruz-López (20 años menor), hija del empresario liberal José Cruz López, consejero accionista del diario El Imparcial y participante en la refundación del diario El Sol a finales de la década de $1910^{59}$. El 14 de enero de 1936, Ricardo y Elena tuvieron juntos a su primer retoño, una niña que llevó el mismo nombre que su madre ${ }^{60}$. La guerra y los traslados de Ricardo los separó durante bastante tiempo. Así, mientras el matemático siguió al Gobierno de la República por sus capitales itinerantes, Elena y su hija se trasladaron de Irún, donde les sorprendió el inicio de la guerra, a Getxo, para residir en la casa que su hermana tenía en la calle de los Chopos. Lógicamente, cuando falleció su suegra en Irún no pudo asistir a su funeral, como a continuación se recoge en el siguiente extracto de El Liberal. Tampoco cuando falleció el padre de Elena unos meses más tarde en Madrid.

La señora doña Mercedes Larrañaga y Colsa falleció en Bilbao el día 30 de mayo de 1937 a los sesenta y tres años de edad. Su esposo José Cruz López (ausente); hijos José (ausente), María (ausente), Mercedes, Pedro (ausente) y Elena; hijos políticos, Carmen Paradís (ausente), Manuel Sánchez Arcos (ausente), Ricardo Vinós (ausente) y José Arregui ${ }^{61}$.

Su fidelidad a la República, pronto, tuvo sus consecuencias. La construcción del nuevo Estado franquista trajo consigo la represión, pero, también, la depuración. Aunque, se crearon diferentes comisiones dedicadas a tal efecto en febrero de 1939, hubo casos de degradación y castigo que se instruyeron al inicio de la guerra ${ }^{62}$. Así, en diciembre de 1936 el gobernador civil y presidente de la

58. "La conveniencia de la evacuación y su organización admirable. Acomodo, alimentación y seguridad de los seres indefensos", ABC, 28-12-1936, p. 7-8. Cfr. Aróstegui, J. y Martínez, J.A., La Junta de Defensa de Madrid, Madrid, 1984, pp. 178-179 y 185-188.

59. "Declaraciones de María Vinós", 11-7-2017, Archivo familiar Vinós.

60. Ampliación de la declaración jurada de D. Ricardo Vinós, 4-7-1939, México, Archivo del Museo Arqueológico de México. Agradezco al profesor José Ángel Ascunce que me proporcionara este documento. Su esposa procedía de una familia nacionalista vasca, vinculada a través de su hermana, con José Arregui, hermano de Luis, el que fuera secretario del Euskadi Buru Batzar del PNV, que, tras la caída del frente norte, se dedicó desde Iparralde a mantener el contacto con los burukides encarcelados en Burgos y otras penitenciarias. Jiménez de Aberásturi, J.C., De la derrota a la esperanza. Políticas vascas durante la Segunda Guerra Mundial, Oñati, 1999, pp. 40, 42, 156, 166 y 294. Mota, D., Un sueño americano. El Gobierno Vasco en el exilio y Estados Unidos (1937-1979), Oñati, 2016, p. 49.

61. El Liberal, 4-6-1937, p. 4.

62. Sobre la depuración franquista en el ámbito educativo hay una gran cantidad de estudios repartidos por provincias, estos son algunos de los más significativos: Ramos, 
comisión creada para depurar la actuación del profesorado en la provincia de Logroño, imputó a Ricardo Vinós Santos, de la Escuela Superior de Trabajo, los siguientes cargos: " $1{ }^{\circ}$ Pertenecer al grupo francamente marxista. $2^{\circ}$ Estar afiliado a izquierdas republicanas; $3^{\circ}$ Faltas a su cátedra de Logroño desde hace cerca de 10 años; $4^{\circ}$ Haber conseguido trato especialísimo de favor y pensiones en el extranjero siempre por medio de la política; $5^{\circ}$ en sus conversaciones alabar la política del triste bienio; $6^{\circ}$ Pertenecer a la institución libre de enseñanza" ${ }^{63}$.

En julio de 1937, el Boletín Oficial del Estado franquista hacía público su cese y degradación:

[...] visto el expediente instruido a D. Ricardo Vinós Santos, profesor de Matemáticas de la Escuela Superior de Trabajo de Logroño, de conformidad con la propuesta de la Comisión de Cultura y Enseñanza, y con arreglo a lo dispuesto en el decreto de 8 de noviembre último y órdenes del 10 del mismo mes y de 17 de febrero pasado, para su aplicación dispongo: la separación definitiva del servicio de D. Ricardo Vinós Santos, debiendo ser dado de baja en su escalafón ${ }^{64}$.

Este tipo de informaciones no provocaron que Vinós se amilanara, sino todo lo contrario. En 1938, ya en Barcelona, fue uno de los firmantes del manifiesto de apoyo a Juan Negrín, quien, en calidad de presidente del Consejo de Ministros había hecho un Ilamamiento a todos los españoles que luchaban por la República. La convicción de Vinós fue plena y así firmó un documento en el que un nutrido grupo de hombres de ciencia, escritores y artistas brindaron pública y solemnemente su adhesión al Gobierno de la República Española y su fidelidad al presidente Negrín, manteniéndose en sus puestos de trabajo en fábricas, escuelas y laboratorios $^{65}$. Así se entiende que, en marzo de 1938, Vinós continuara presente en aquellas iniciativas relacionadas con la educación y la formación profesional, siendo miembro activo de la Junta Central de Formación Profesional encargada de inspeccionar los centros públicos y de seleccionar al profesorado ${ }^{66}$.

S., "Maestros y maestras de primera enseñanza bajo la dictadura franquista", en Cuesta, J. (coord.), La depuración de funcionarios bajo la dictadura franquista (1939-1975), Madrid, 2009, pp. 52-63. González, G., El nacimiento de la universidad franquista: la depuración republicana y franquista de los catedráticos de universidad, Madrid, 2001. Morente, F., "La depuración franquista del magisterio público: un estado de la cuestión", en Hispania: Revista española de historia, n 208, vol. 61, 2001, pp. 661-688. Agulló, C. y Fernández, J.M., "La depuración franquista del profesorado de las Escuelas Normales de Alicante, Castellón y Valencia", en Revista de Educación, n 364, 2014, pp. 197-221.

63. AGACE-SEC, leg. 14535-105 y leg. 1555-31. Documentos citados en Llombart, "Matemáticos españoles", op. cit., pp. 201-234.

64. Boletín Oficial del Estado, no 280, Burgos, 27-7-1937.

65. La Vanguardia, 1-3-1938, p. 2.

66. Carta del jefe de la sección de enseñanza técnica y profesional del ministerio de instrucción pública y sanidad, 5-3-1938, Barcelona, Archivo familiar Vinós. 
Pero, el mantenimiento de esta relativa normalidad se agotó en diciembre de 1938, cuando las tropas franquistas iniciaron la ofensiva sobre Cataluña. Los nervios y el miedo a la represión, ya anunciada en el caso de Vinós, provocó que, en enero de 1939, apenas unos días antes de la caída de Barcelona, el matemático marchara en coche a Francia vía Cerviá de Ter. Pero, no viajó sólo. Un grupo bastante amplio de intelectuales y políticos entre los que se encontraban José Puché, Joaquín Xirau, Antonio Machado, Navarro Tomás, Carles Riba, los hermanos Trías, Gori Muñoz y otras personalidades le acompañaron en un destierro que, Enrique Rioja describió de la siguiente manera, una vez que llegaron a Cerbère (Francia): "a la puerta del café de la estación, que recogió su primer sentir desterrado; pocas palabras, cargadas de emoción" ${ }^{\prime 67}$.

\section{Exilio}

Exiliado en París, su cercanía a la intelectualidad republicana se hizo más patente al formar parte de la Junta de Cultura Española, que había sido creada en marzo de 1939 en la Rue St. Jacques, sede del Centro Cervantes de París. Esta institución compuesta, además de por Vinós, por José Bergamín, Juan Larrea, Pablo Picasso, Rodolfo Halfter, José Bejarano y Josep Carner, entre otros, fue una iniciativa de la Delegación de la Junta de Relaciones Culturales, adscrita a la Embajada de España en París, que impulsó el SERE como último recurso de la República para evitar la disolución de la intelectualidad española ${ }^{68}$. Así, aparte de impulsar un órgano de difusión, la revista España Peregrina, se marcaron como objetivos: organizar la defensa intelectual de la causa republicana, propagando sus contenidos por Latinoamérica, región atractiva para el exilio intelectual; unir y ayudar a los trabajadores exiliados; y evitar la disgregación de los expatriados ${ }^{69}$.

Con todo, lo primero que hizo la Junta fue intentar trasladar su sede de París a Latinoamérica, cosa que consiguieron la mayoría de sus miembros embarcando

67. Rioja, E., "Último sol en España", Diálogo de las Españas, 4-5, 1, 32, 33. Cfr. Agramunt, F., Arte en las alambradas. Artistas españoles en campos de concentración, exterminio y gulags, Valencia, 2016. Pérez Peña, F., Exilio y depuración en la Facultad de Medicina de San Carlos (sus profesores y la Guerra Civil), Madrid, 2005, p. 198.

68. Cabañas, M., "Picasso y su ayuda a los refugiados españoles en los campos de concentración franceses", en Actas del Congreso Internacional la Guerra Civil España (1936-1939), Madrid, 2006.

69. Aduriz, I. y Zabala, J.R., "La revista España Peregrina (México 1940)", en Kultura: cuadernos de cultura, 9, 1986, pp. 121-132. Ramón Xirau en "Saludo a España Peregrina", señala al respecto: "el 13 de marzo de 1939, pocos días antes de la caída de Madrid, se fundó en París la Junta de Cultura Española presidida por Bergamín, Josep Carner, Juan Larrea y -miembros de ella- Juan M. Aguilar, Robert F. Balbuena, Corpus Barga, Carrasco Garrorena, Gallegos Rocafull, Rodolfo Halffter, Emilio Herrera, Manuel Márquez, Agustín Millares, Tomás Navarro Tomás, Isabel de Palencia, Pablo Picasso, Augusto Pi Sunyer, Enrique Rioja, Luis Santullano, Ricardo Vinós, Joaquín Xirau. Secretario: Eugenio Imaz", en Larrea, J., "Actividades de la Junta de Cultura Española", España Peregrina, pp. 42-43, documento citado en Ascunce, Topías y utopías de Eugenio Imaz, op. cit., p. 138. 
en el buque Sinaia. Iniciada la II Guerra Mundial, cerca de 100.000 españoles regresaron a España desde Francia, pero algunos, una parte importante, emigró a México. Durante el otoño de 1939, gracias al SERE, numerosos exiliados españoles se trasladaron de Francia a México. En este punto, la expedición del Sinaia fue fundamental, sumado a las de Ipanema y Mexique, ya que permitió la llegada de unos 24.000 españoles entre 1939 y $1950^{70}$. Si bien, cabe destacar igualmente la del buque holandés Veendam, que fue utilizada por un nutrido grupo de personas en torno a la Junta de Cultura Española, entre ellos, Ricardo Vinós, Eduardo Ugarte, Josep Carner, Josep Renau y Teresa Serna de Rodríguez Luna ${ }^{71}$.

En mayo de 1939, desembarcó en Nueva York y acto seguido el matemático vasco, junto con otras personalidades de la Junta, entre ellas, Bergamín, Larrea y Renau, se dirigieron en autobús a México D.F.; un viaje que fue toda una experiencia, mucho menos traumática que la huida a Francia por Girona, al que ayudó el carácter feliz y optimista de Vinós, convertido en "el alma del viaje", según declaró Fernando Giner de los Ríos ${ }^{72}$. Ya en México, lo primero que hizo Vinós fue presentarse ante las autoridades de inmigración, prestar declaración jurada sobre él y su familia y ser examinado por los funcionarios de inmigración. En la tarjeta de identificación que el Departamento de Migración emitió a su nombre quedaron reflejados sus características y complexión: altura $(1,68 \mathrm{~m})$, moreno, pelo negro, fuerte, con rasgos italo-británicos ${ }^{73}$. Superados estos trámites continuó al frente del cargo que le había encomendado el Gobierno de la República antes de marchar al exilio: Director General de Enseñanza Técnica y Profesional ${ }^{74}$.

Sin embargo, le resultaba difícil poder concentrarse. Se encontraba a miles de kilómetros de su hogar, donde había dejado a su mujer e hija en condiciones francamente difíciles. Su objetivo de vida: ayudar económicamente a su familia para conseguir el dinero de un pasaje de barco lo más pronto posible para ellas. Vinós, al igual que todo el exilio, se enfrentó a problemas económicos. Desde el primer

70. Alted, La voz de los vencidos, op. cit., p. 222.

71. Plaza, A., "Intelectuales hacia México: el viaje del Veendam. Un episodio simbólico en la historia del exilio republicano de 1939", en Aznar, M. et al. (coord.), El exilio republicano de 1939 y la segunda generación, Sevilla, 2011, pp. 830-844. Gil Fombellida, M. K., "Teatros del exilio vasco", en González Allende, I. (ed), El exilio vasco. Estudios en homenaje al profesor José Ángel Ascunce Arrieta, Bilbao, 2016, p. 130. Cabañas Bravo, M., "Quijotes en otro suelo, artistas españoles exiliados en México", en Murga, l. et al. (coord.), Analogías en el arte, la literatura y el pensamiento del exilio español de 1939, Madrid, 2010, p. 32. García, M., Memorias de Posguerra. Diálogos con la cultural del exilio (1939-1975), Valencia, 2014.

72. Declaraciones de Fernando Giner de los Ríos (poeta, 1917-1995) a Ricardo Vinós López, sin fecha, Archivo familiar Vinós.

73. Ficha de Ricardo Vinós Santos, Secretaría de Gobernación de México, Registro Nacional de Extranjeros en México, Departamento de Migración, Archivo General de la Nación, 7-7-1939, AGA, RIEM, 276, 170.

74. Carta de Ricardo Vinós al presidente del Consejo del SERE, 31-7-1939, México, Archivo del Museo Arqueológico de México. 
momento, el Gobierno Republicano arrastró problemas financieros para intentar mantener sus instituciones y a duras penas consiguió mantenerlas. Por eso, cuando Vinós se dirigió al SERE para denunciar la mala situación económica que estaba atravesando, exigiendo un aumento de su subsidio para poder ayudar a su familia que estaba en Bilbao en una "situación [que] exige ayuda económica", el presidente de dicho organismo, su amigo y compañero, José Puche le contestó sin ambages que "dicha entidad sólo puede auxiliar a los refugiados políticos españoles que, con sus familiares, se encuentren residiendo en México"75. Una respuesta que pese a ser lógica, no era la esperada por el profesor, que tuvo que resignarse y concentrarse en encontrar otra vía para conseguir reencontrarse con su familia.

Mientras tanto, continuó trabajando en el ámbito educativo. Así, en agosto de 1939 formó parte del tribunal que designó al cuerpo de maestros que compondrían el colegio español Luis Vives ${ }^{76} ;$ y, poco después, en los albores de 1940, trabajó en la construcción e impulso de la Academia Hispano Mexicana, de la que fue director gerente ${ }^{77}$. Esta institución fue su proyecto estrella y a él dedicó toda su vida en México, ayudado por Lorenzo Alcaraz y Vicente Carbonell, junto un patronato directivo compuesto por Aarón Sáenz, Carlos Obregón, Gonzalo Robles, David Cosío Villegas, Juan Roura y Josep Carner ${ }^{78}$. Si bien, había habido proyectos anteriores, como el colegio Ruíz de Alarcón, que se fundó con dinero mexicano en 1939, contando con una nómina de profesores de impresionante calidad, pero, por diferentes motivos no llegó a cuajar ${ }^{79}$.

A diferencia de otras escuelas fundadas por exiliados republicanos en México, la Academia Hispano Mexicana puso mucho énfasis en la educación científica, marcando distancia con otros proyectos como el del Colegio Madrid, cuya plantilla de profesorado fue más humanista. No fue, sin embargo, la única diferencia. Junto a los distintos proyectos que se acaban de mencionar, cabe destacar que la Academia Hispano Mexicana fue la entidad educativa que ob-

75. Ibíd. Carta de José Puche a Ricardo Vinós, 14-8-1939, México, Archivo del Museo Arqueológico de México.

76. Carta de José Puche a Ricardo Vinós, 29-8-1939, México, Archivo del Museo Arqueológico de México.

77. Enríquez Calleja, I., "Dr. Ricardo Vinós Santos, in memoriam", en Ciencia: revista hispano-americana de Ciencias Puras y Aplicadas, n 11-12, vol. XIX, 1959, p. 267.

78. Laso, J.M., "El exilio científico española", en Ábaco: Revista de Cultura y Ciencias Sociales, no 42, 2004, pp. 49-60. García de Fez, S., "Una escuela desconocida del exilio: la polémica en torno al instituto hispano-mexicano Ruíz de Alarcón", en Educació i historia: Revista d'història de l'educació, nº 17, 2011, pp. 211-235.

79. Giral, F., Ciencia española en el exilio (1939-1989). El exilio de los científicos españoles, Barcelona, 1994, p. 84. Respecto al Instituto Luis Vives y otras instituciones educativas: García Camarero, E., La Ciencia Española entre la polémica y el exilio, pasando por el Ateneo de Madrid y la Junta para la ampliación de estudios, Madrid, 2012, p. 223. Cruz, J.I., "El instituto Luis Vives. Colegio Español de México", en Revista Española de Pedagogía, no 193, año L, septiembre-diciembre 1992, pp. 527-544. 
tuvo mejores resultados, pero, también fue la que con más énfasis buscó establecer lazos con la sociedad mexicana. Así, mientras el Colegio Luis Vives y el Madrid fueron apadrinados por el SERE y la Junta de Ayuda a los Republicanos Españoles (JARE), respectivamente, el Ruíz de Alarcón y la Academia Hispano Mexicana aspiraron a ser más heterogéneas, difuminando sus orígenes, sin centrarse exclusivamente en la enseñanza sobre cuestiones españolas, y proponiendo una oferta educativa de calidad dirigida a aquella población mexicana que pudiera "costear sus estudios y mantener la actividad docente" ${ }^{80}$.

Gracias a este planteamiento, la Academia Hispano Mexicana consiguió establecer un contrato con la Secretaría de Educación Pública de México y la Universidad Nacional Autónoma de México, cuya principal inspiración fue la creación de un centro de Enseñanza Secundaria y Preparatoria, Ingeniería y Arquitectura que mejorara la calidad educativa del país ${ }^{81}$. Como se ve en la siguiente carta, Gustavo Baz le dijo a Alfonso Reyes, presidente de la Casa de España en México, que le interesaba el proyecto de Vinós:

Usted sabe que tengo el propósito de cooperar en todo lo posible para el desarrollo de la educación superior, procurando, ante todo, que las Escuelas Secundarias y Preparatorias del país preparen cada vez mejor a los alumnos que de ellas salen para que las universidades puedan cumplir con su cometido más eficientemente contando con alumnos bien preparados ${ }^{82}$.

Para su creación, Vinós y Carner, se pusieron en contacto con el subsecretario de Hacienda en México, Eduardo Villaseñor para solicitarle 20.000 pesos y, a cambio, permitir cierta intervención del gobierno mexicano en algunos aspectos, como así acabó sucediendo ${ }^{83}$. Así, conforme fue avanzando el proyecto educativo de Vinós, se fue alejando del proyecto inicial, que comenzó a controlar la JARE en sustitución del SERE, pues lo que le interesaba en realidad era implementar un proyecto pedagógico desde la base y, a su juicio, eso sólo era posible creando una escuela en la que el alumno pudiera entrar en el jardín de infancia y salir graduado en estudios superiores ${ }^{84}$.

80. García de Fez, S., "España en México. El aula como reconstrucción política y nacional: los colegios del exilio republicano español en la ciudad de México", en III, Foro Ibérico de Museísmo Pedagógico, V Jornadas Científicas de la SEPHE, p. 64.

81. Carta de Alfonso Reyes a Ricardo Vinós, 12-12-1939, México D.F., Archivo familiar Vinós. Cfr. Abellán, J.L. y Monclús, A., El pensamiento español contemporánea y la idea de América. II. El pensamiento en el exilio, Barcelona, 1989, p. 149.

82. Carta de Gustavo Baz a Alfonso Reyes, 8-12-1939, México DF, Archivo familiar Vinós.

83. Carta de Alfonso Reyes a Eduardo Villaseñor, Ciudad de México, 19-6-1940, AHCM, en Morán, B., "Los que despertaron vocaciones y levantaron pasiones. Los colegios del exilio en la ciudad de México", en Sánchez, A. y Figueroa, S., De Madrid a México. El exilio español y su impacto sobre el pensamiento, la ciencia y el sistema educativo mexicano, Michoacán, 2002, pp. 209-245.

84. Declaraciones de María Vinós, 11-7-2017, Archivo familiar Vinós. 
La Academia Hispano Mexicana se fundó en el Paseo de la Reforma número 80 de México DF, en el palacete de la Glorieta de Colón. Inicialmente, sólo se impartieron enseñanzas de secundaria y preparatoria, aunque, paulatinamente, fue abriéndose a otros niveles, a la par que impulsó una vida cultural muy rica, organizando visitas a museos, exposiciones, charlas y conferencias del exilio intelectual español ${ }^{85}$. Desde el primer momento, el matemático Lorenzo Alcaraz y Ricardo Vinós, director de la academia, marcaron la tónica y la dinámica de su funcionamiento, y se esforzaron por conseguir la financiación necesaria para que la Academia contara con las prestaciones básicas para su alumnado ${ }^{86}$. Según el testimonio de alguno de sus antiguos alumnos, ello se debía al carácter metódico de Vinós:

una persona muy rígida, muy buen maestro y ejemplo de hombre trabajador. Vinós tenía diez grupos de 40 alumnos cada uno y todos los días dejaba tarea, así que diariamente corregía 400 tareas. Él decía años después que era muy fácil, pero yo me acuerdo que las leía todas, porque nos corregía hasta los acentos. Vivía enfrente de la Academia así que sólo cruzaba a su casa para ir a dormir. El ambiente de la Academia era muy estimulante [ ] Había total atención a los alumnos por parte de todos los maestros, en especial de Vinós ${ }^{87}$.

Conforme se iban produciendo nuevos avances en la vida profesional del matemático alavés, se produjeron también cambios en su vida personal. En octubre de 1940, obtuvo la nacionalidad mexicana y, por fin, el 29 de noviembre de 1941, después de casi dos años de espera, vía la Habana, se reencontró con su mujer y su hija Elena ${ }^{88}$. Desde aquel momento, Vinós sólo se preocupó por su familia (ampliada el 11 de enero de 1943 con el nacimiento del pequeño Ricardo), la Academia y la Ciencia. Durante toda su vida, su vocación fue su razón de ser, prueba de ello es que viviera prácticamente en la Academia y, precisamente, fue estando allí cuando le visitó la mala fortuna. En agosto de 1959, cuando se encontraba en su despacho de la Academia, situado en la calle Abraham González 67, y después de haber impartido una de sus clases, Ricardo Vinós Santos sufrió un infarto de miocardio que le causó la muerte. Según su

85. De Luis, F., "El exilio de la Federación Española de Trabajadores de la Enseñanza en México (1939-1949)", en Tzintzu: Revista de Estudios Históricos, 63, enero-junio 2016, p. 238.

86. En octubre de 1941, Vinós escribió a la JARE solicitando la subvención de 7.500\$ como "anticipo a cuenta de los honorarios que a la Academia puedan corresponder por las atenciones docentes a los alumnos que disfrutan en ella de las becas que $V d s$. les tienen concedidas", pero fue denegado un mes más tarde. Carta de Ricardo Vinós a Carles Esplá, México, 16-10-1941, Centro Documental de la Memoria Histórica (CDMH), Incorporados 47, sig. 3.4a/3518a. Cfr. Carta de Ricardo Vinós a la JARE, 16-10-1941, México DF, CDMH, Incorporados 47, sig. 3.4a/3518b.

87. Morán, "Los que despertaron vocaciones y levantaron pasiones", op. cit., p. 209-245.

88. Ficha de Elena Cruz López de Vinós, Secretaría de Gobernación de México, Registro Nacional de Extranjeros en México, Departamento de Migración, Archivo General de la Nación, 29-11-1941, sig. AGA, RIEM, 276, 171. 
acta de defunción, certificada por el médico-forense Santiago Villanueva Sánchez, falleció el 24 de agosto de 1959 (y no en 1957, como queda reflejado en algunas fuentes) a la edad de 71 años $^{89}$. Tras su fallecimiento, de entre los intelectuales que realizaron una semblanza para recordar al matemático sobresalió la de Isidoro Enríquez, muy próxima a lo que ya se dijo en vida de Vinós:

Vinos era un hombre de destino [...] Por enseñar afrontó sacrificios inauditos que le minaron el corazón de emociones fuertes y de gratules fatigas. [...] un verdadero franciscano: sin miedo a la falta de recursos económicos [...] pedía ayuda [...] ansioso de sacar de sus aulas, al servicio de México, ingenieros, arquitectos, matemáticos, literatos y artistas [...] prodigó en México su inefable esfuerzo de matemático singular. [...] la finura de su espíritu [...] templó su alma en todas las disciplinas del saber — música, pintura, literatura-, como uno de aquellos personajes renacentistas a quienes nada les era ajeno. [...] enseñó matemáticas cual orfebre de esa pedagogía dificilísima, el paradigma de su tesón lo ha proyectado a la posteridad como educador extraordinario. $Y$ fue precisamente el exceso de trabajo quien precipitó el final. [...] manteniendo la máquina a todo vapor, el corazón se paró un día infausto para los que le queríamos y admirábamos sin reservas. [...]Nunca habíamos pensado que un hombre tan vigoroso nos fuese a abandonar repentinamente. [...] Un virtuosismo como el suyo, en las aulas, merecía la recompensa inapreciable de poner a los pies de España generaciones de matemáticos preparados silenciosamente por él, en una época asaz claudicante y de bastardas ambiciones ${ }^{90}$.

Pese al fallecimiento de su principal impulsor, la Academia continuó adelante gracias a Lorenzo Alcaraz, que la dirigió hasta la década de 1970, pero convirtiendo la institución pública de Vinós en una empresa privada ${ }^{91}$. Diferente fue el caso de Elena Cruz-López, que tras la muerte de su marido decidió regresar a España en 1961 dejando en México a sus hijos con su vida bastante encarrila$\mathrm{da}^{92}$. Regresó para afianzar las posesiones que le quedaban a su familia en Madrid. Para ello, tuvo que quedarse en España una larga temporada para, de este modo, obtener la ciudadanía y poder reclamar sus derechos de propiedad sobre el legado familiar. Sin duda, un capítulo muy duro, pues fueron varios años los que tuvo que residir sola en Madrid, mientras nacían sus primeros nietos ${ }^{93}$.

89. Acta de defunción de Ricardo Vinós, 25-08-1959, México, Archivo familiar Vinós.

90. Enríquez, "Ricardo Vinós", op. cit., p. 268.

91. Flores, M.G., Lorenzo Alcaraz Segura: otro personaje extremeño del exilio republicano, Badajoz, 2013, p. 662.

92. Declaraciones de María Vinós, 11-7-2017, Archivo familiar Vinós.

93. Declaraciones de María Vinós, 29-7-2017, Archivo familiar Vinós. 


\section{Conclusiones}

Como se ha señalado en la introducción, a lo largo de este artículo se ha intentado arrojar algo más de luz sobre la figura de este matemático alavés. Se ha profundizado en las etapas más desconocidas de su biografía, las del primer tercio del siglo XX, y se ha intentado aclarar algunos aspectos sobre su vida que carecían de base argumentativa, como el hecho de que algunas fuentes adelantaran hasta en dos años la fecha de su fallecimiento. Ahora se conoce con mayor precisión su papel durante la Segunda República y la Guerra Civil, pero, sin embargo, se desconocen los pormenores de su estancia en Valencia y Barcelona, así como los entresijos de su exilio en México, principalmente, en lo que se refiere a su presencia en los foros de debate y congresos matemáticos entre 1940 y 1959. Ello se debe a que se carece de suficiente documentación sobre su figura, como ha ocurrido con muchos otros exiliados, y a la falta de una mayor profundización en los archivos mexicanos.

En este caso, se han podido ofrecer algunos datos inéditos, gracias a que se ha contado con cierta ventaja: la predisposición de su familia para dar a conocer la figura de Ricardo Vinós. Por último, este acercamiento a la figura de Vinós no es, ni mucho menos, algo definitivo. Más bien es una invitación a otros investigadores que quieran profundizar en los estudios sobre este matemático alavés, porque aún hay muchos vacíos que deben ser paliados en torno a su labor docente y científica en México, la cual, según adujeron sus coetáneos, como Isidoro Enríquez, tuvo una especial repercusión. Queda, pues, pendiente la consulta de la documentación depositada en México y el análisis específico de sus estancias investigadoras y congresuales en Latinoamérica, pues el análisis de la revista Ciencia: revista hispano-americana de ciencias puras y aplica$d_{a s}{ }^{94}$, a la que se ha tenido acceso durante la redacción de este artículo y en la

94. Ciencia. Revista hispano-americana de ciencias puras y aplicadas nació en marzo de 1940 en México con el objetivo de divulgar el conocimiento científico y sus progresos, en las áreas físico-naturales y exactas, y sus diferentes aplicaciones. Desde el primer momento, su vocación fue eminentemente pública y su finalidad fue incentivar el interés de la sociedad por el estudio de estas disciplinas en los países hispanoamericanos. Asimismo, la revista se creó para ser publicada mensualmente y paliar así la lentitud con la que aparecían los avances científicos en las revistas especializadas. Ciencia se publicó hasta 1975 con ciertas intermitencias y pasó de la mensualidad a la bimensualidad a lo largo de la década de 1950. Su mantenimiento en este amplio abanico de tiempo responde a la excelente relación que los promotores de la revista mantuvieron con el Gobierno de México, que les apoyó moral y económicamente. Dirigida e impulsada por Ignacio Bolívar Urrutia hasta su fallecimiento en 1945, sus sucesores hicieron todo lo posible por mantenerla: desde Cándido Bolívar hasta José Puche, su último director. La revista adquirió un gran renombre a la altura de 1950 y en ella publicaron destacados profesores universitarios. Véase Carapeto, C. Aportaciones a la ciencia de los investigadores españoles exiliados a partir de un estudio bibliométrico de la revista Ciencia (1940-1975), Badajoz, 2005. Carapeto, C., Pulgarín, A. y Cobos, J. M. "CIENCIA, Revista hispano-americana de ciencias puras y aplicadas (1940-1975) [I]", en LLULL, 25(43), 2002, pp. 329-368. 
que se pensaba que Vinós jugó un papel clave como investigador y escritor, ha desmentido que el matemático alavés publicara artículos de carácter científico en la misma y que tuviera un papel tan activo.

Vinós colaboró asiduamente en Ciencia, pero, en materia logística, ofreciendo a la dirección de ésta locales para su funcionamiento y establecimiento de su secretaría, como confirma la siguiente nota:

Con este motivo la dirección de CIENCIA, hace patente su agradecimiento al Doctor Ricardo Vinos, director de la Academia Hispano-Mexicana, y al Ing. José Alcaraz, secretario de dicho centro, por haber hecho galantemente el ofrecimiento de un local para la revista, en el centro que dirigen ${ }^{95}$.

Un ofrecimiento que, a la postre, fue confirmado por la propia dirección de la revista en una carta al lector firmada por su director Cándido Bolívar, que agradeció el gesto. Dicho artículo fue el principio de una serie de reconocimientos que la dirección de la revista repetiría de manera asidua en los números publicados posteriormente:

La secretaría de "CIENCIA" ha estado instalada desde principio de 1947 en local cedido desinteresadamente por la Academia HispanoMexicana, por lo cual el Patronato expresa su agradecimiento al director de dicho centro docente Dr. Ricardo Vinos ${ }^{96}$.

Ahora bien, no debe olvidarse que la consulta de la mencionada revista sí que confirma otras cosas en lo que a se refiere a las contribuciones por escrito, que Vinós tuvo una participación menor en Ciencia y que se limitó a la realización de reseñas sobre libros de importante calado científico como la que hizo sobre el libro de Frank Gaynor Enciclopedia de bolsillo de Energía Atómica en el número 5-6 de agosto de 1950, aunque hubo más en números subsiguientes ${ }^{97}$. De hecho, por las fuentes a las que se ha tenido acceso, dejando al margen lo ya señalado, el examen de esta revista demuestra que realmente Vinós se dedicó más a las labores docentes en la Academia Hispano Mexicana que a la investigación. Se insiste, por ello, una vez más, en la necesidad de consultar los fondos mexicanos, fundamentalmente los de los archivos nacionales y los contenidos en la Academia Hispano-Mexicana.

95. "Noticias. México", Ciencia. Revista hispano-americana de ciencias puras y aplicadas, Vol. VII, nº 7-8, 24-10-1946, p. 235.

96. Bolívar, C. "Al lector", Ciencia. Revista hispano-americana de ciencias puras y aplicadas, 9 (1-3), 15-12-1948, p. 6.

97. Vinós, R. "Libros", Ciencia. Revista hispano-americana de ciencias puras y aplicadas, 10 (5-6), 5-08-1950, p. 183. 


\section{Bibliografía}

Abellán, J. L. y Monclús, A., El pensamiento español contemporánea y la idea de América. II. El pensamiento en el exilio, Barcelona, 1989.

Aduriz, I. y Zabala, J. R., "La revista España Peregrina (México 1940)", Kultura: cuadernos de cultura, 9, 1986, pp. 121-132.

Agramunt, F., Arte en las alambradas. Artistas españoles en campos de concentración, exterminio y gulags, Valencia, 2016.

Agulló, C. y Fernández, J. M., "La depuración franquista del profesorado de las Escuelas Normales de Alicante, Castellón y Valencia", Revista de Educación, 364, 2014, pp. 197-221.

Alted, A. y Domergue, L. (coord.), El exilio republicano español en Toulouse, 1939-1999, Madrid, 2003.

Alted, A., La voz de los vencidos. El exilio republicano de 1939, Madrid, 2005.

Aróstegui, J. y Martínez, J. A., La Junta de Defensa de Madrid, Madrid, 1984.

Ascunce, J. A., Topías y utopías de Eugenio Imaz. Historia de un exilio, Barcelona, 1991.

Avilés, J., "Francia y la guerra civil española. Los límites de una política", Espacio, tiempo y forma. Serie V, Historia Contemporánea, 5, 1992, pp. 165-184.

Bermejo Martín, F., La Rioja contemporánea 1784-1996, Logroño, 2013.

Bosch, A., Miedo a la democracia. Estados Unidos ante la Segunda República y la guerra civil española, Barcelona, 2012.

Caballero, Á., "La educación en la Segunda República (1931-1937)”, en Vico, M. (coord.), Educación y cultura en la Málaga contemporánea, Málaga, 1995, pp. 135-164.

Cabañas Bravo, M., "Quijotes en otro suelo, artistas españoles exiliados en México", en Murga, I. et al. (coord.), Analogías en el arte, la literatura y el pensamiento del exilio español de 1939, Madrid, 2010.

Cabañas, M., "Picasso y su ayuda a los refugiados españoles en los campos de concentración franceses", en Actas del Congreso Internacional la Guerra Civil España (1936-1939), Madrid, 2006.

Carapeto, C., Aportaciones a la ciencia de los investigadores españoles exiliados a partir de un estudio bibliométrico de la revista Ciencia (1940-1975), Badajoz, 2005.

Carapeto, C., Pulgarín, A. y Cobos, J. M., "CIENCIA, Revista hispano-americana de ciencias puras y aplicadas (1940-1975) [I]", LLULL, 25 (43), 2002, pp. 329-368.

Casanova, J., República y Guerra Civil, Barcelona, 2007.

Cerrillo Rubio, M. I., La formación de la ciudad contemporánea. Logroño entre 1850 y 1936, Logroño, 1993. 
Climent López, E., El proceso de industrialización de La Rioja. Logroño, 1992, en García Prado, Justiniano. Historia de la Rioja, Logroño, 1983.

Cruz, J. I., "El instituto Luis Vives. Colegio Español de México", en Revista Española de Pedagogía, no 193, año L, septiembre-diciembre 1992, pp. 527-544.

De Luis, F., "El exilio de la Federación Española de Trabajadores de la Enseñanza en México (1939-1949)", Tzintzun: Revista de Estudios Históricos, 63, 2016, pp. 207-241.

De Llera, L., El último exilio español en América: grandeza y miseria de una formidable aventura, Madrid, 1996.

De Madariaga, C., La formación profesional de los trabajadores, Madrid, 1933.

Del Molino, S., La España vacía. Viaje por un país que nunca fue, Madrid, 2015.

Delgado Idarreta, J. M., "La Rioja", en Varela Ortega, J. (dir.), El poder de la influencia. Geografía del caciquismo en España (1875-1923), Madrid, 2001, pp. 497-514.

Español, L., "Presencia de matemáticos en La Rioja como socios de la Real Sociedad Matemática Española durante el periodo 1911-1960", Zubía: revista de ciencias, 33-34, 2015-2016, pp. 7-28.

Flores, M. G., Lorenzo Alcaraz Segura: otro personaje extremeño del exilio republicano, Badajoz, 2013.

García Camarero, E., La Ciencia Española entre la polémica y el exilio, pasando por el Ateneo de Madrid y la Junta para la ampliación de estudios, Madrid, 2012.

García de Fez, S., "Una escuela desconocida del exilio: la polémica en torno al instituto hispano-mexicano Ruíz de Alarcón", Educació i historia: Revista d'història de l'educació, 17, 2011, pp. 211-235.

García de Fez, S., "España en México. El aula como reconstrucción política y nacional: los colegios del exilio republicano español en la ciudad de MéxiCo", en III Foro Ibérico de Museísmo Pedagógico, V Jornadas Científicas de la $S E P H E$, pp. 61-74.

García, M., Memorias de Posguerra. Diálogos con la cultural del exilio (19391975), Valencia, 2014.

Gil Fombellida, M. K., "Teatros del exilio vasco", en González Allende, I. (ed), El exilio vasco. Estudios en homenaje al profesor José Ángel Ascunce Arrieta, Bilbao, 2016.

Giral, F., Ciencia española en el exilio (1939-1989). El exilio de los científicos españoles, Barcelona, 1994.

Gómez Calvo, J., Matar, purgar, sanar. La represión franquista en Álava, Madrid, 2014.

González, G., El nacimiento de la universidad franquista: la depuración republicana y franquista de los catedráticos de universidad, Madrid, 2001.

Herrero, C., "Nota sobre la educación en la Segunda República Española", Didácticas Específicas, 13, 2015, pp. 186-191. 
Jiménez de Aberásturi, J. C., De la derrota a la esperanza. Políticas vascas durante la Segunda Guerra Mundial, Oñati, 1999.

Juliá, S., Historias de las dos Españas, Madrid, 2010.

Laso, J. M., "El exilio científico española", Ábaco: Revista de Cultura y Ciencias Sociales, 42, 2004, pp. 49-60.

Lines, A., "La matemática en la Rioja en el primer tercio del siglo XX y años de su entorno", Zubía: revista de ciencias, 15, 1997, pp. 121-129.

Llombart, J., "Matemáticos españoles del exilio. Notas biográfico científicas correspondientes a los años previos a la guerra civil", en Sánchez, G. y García de León, P., Los científicos del exilio español en México, Michoacán, 2001, pp. 201-234.

Lloréns, V., "La emigración republicana de 1939", en Abellán, J. L. (dir.), El exilio español de 1939, T.1, Madrid, 1976.

Martínez Navas, I., "La Escuela Industrial y de Artes y Oficios de Logroño", en REDUR II, 2013, pp. 73-106.

Matasci, D., "L'education, terrain d'action internationale: le Bureau International de l'enseignement technique dans les années 1930", Relations Internationales, 151 (3), 2012, pp. 37-48.

Mayoral, V., "El Consejo Nacional de Educación: origen y transformaciones", Revista de Educación, 240 (9), 1975, pp. 127-140.

Monteagudo, M. J. y Chisvert, M., "Los inicios de la psicotecnia en España: el trabajo del Instituto de Reeducación de inválidos del trabajo de Carabanchel (19221929)", Revista de Historia de la Psicología, 28 (2/3), 2007, pp. 189-196.

Moradiellos, E., La perfidia de Albión: el gobierno británico y la guerra civil española, Madrid, 1996.

Morán, B., "Los que despertaron vocaciones y levantaron pasiones. Los colegios del exilio en la ciudad de México", en Sánchez, A. y Figueroa, S., De Madrid a México. El exilio español y su impacto sobre el pensamiento, la ciencia y el sistema educativo mexicano, Michoacán, 2002, pp. 209-245.

Moreno Gómez, F., "La represión en la posguerra", en Juliá, S. et al., Víctimas de la guerra civil, Madrid, 1999.

Morente, F., "La depuración franquista del magisterio público: un estado de la cuestión", Hispania: Revista española de historia, 208, 2001, pp. 661-688.

Mota, D., Un sueño americano. El Gobierno Vasco en el exilio y Estados Unidos (1937-1979), Oñati, 2016.

Ordoñez, M., "Científicos vascos del exilio español", en Garritz, A., Los vascos en las regiones de México, siglos XVI-XX, Tomo III, México, 1997, pp. 299-307.

Ordoñez, M., El Comité Técnico de Ayuda a los Republicanos Españoles: historia y documentos, 1939-1940, México, 1997.

París, C., "Educación y cultura en la Segunda República", en Rodríguez, J., La República y la cultura. Paz, guerra y exilio, Madrid, 2009, pp. 253-260. 
Peralta, J., "Sobre el exilio matemático de la guerra civil española (I)", Suma: Revista sobre enseñanza y aprendizaje de las matemáticas, 56, 2007, pp. 11-21.

Peralta, J., "Sobre el exilio matemático de la guerra civil española (II)", Suma: Revista sobre enseñanza y aprendizaje de las matemáticas, 57, 2008, pp. 9-22.

Pérez Galán, M., La Enseñanza en la Segunda República, Madrid, 2011, pp. 300-324.

Pérez Peña, F., Exilio y depuración en la Facultad de Medicina de San Carlos (sus profesores y la Guerra Civil), Madrid, 2005.

Plá, D., "1939", en Canal, J. (ed.), Exilios. Los éxodos políticos en la Historia de España, siglos XV-XX, Madrid, 2007.

Plaza, A., "Intelectuales hacia México: el viaje del Veendam. Un episodio simbólico en la historia del exilio republicano de 1939", en Aznar, M. et al. (coord.), El exilio republicano de 1939 y la segunda generación, Sevilla, 2011, pp. 830-844.

Preston, P., Las tres Españas del 36, Madrid, 2015.

Ramos, S., "Maestros y maestras de primera enseñanza bajo la dictadura franquista", en Cuesta, J. (coord.), La depuración de funcionarios bajo la dictadura franquista (1939-1975), Madrid, 2009, pp. 52-63.

Rico Gómez, M. L., "La enseñanza profesional y las clases medias técnicas en España (1924-1931)", Hispania, 72, 240, 2012, pp. 119-146. https://doi. org/10.3989/hispania.2012.v72.i240.366.

Rivera A., y De Pablo, S., Profetas del pasado. Las derechas en Álava, VitoriaGasteiz, 2014.

Romero, M., La oposición durante el franquismo. 3. El exilio republicano, Madrid, 2005.

Rubio, J., La emigración de la guerra civil de 1936-1939, Vol. I., Madrid, 1977.

Ruíz, G., Álava, una provincia en pie de guerra. Voluntariado y movilización durante la Guerra Civil, Bilbao, 2016.

Sanz Legaristi, P. y Rivera, A., "Las elecciones al Ayuntamiento vitoriano durante la Restauración", Vasconia: cuadernos de sección Historia y Geografía, 8, 1986, pp. 117-134.

Saz, I., Fascismo y franquismo, Valencia, 2004.

Sesma Muñoz, J. Á. et al. Historia de la ciudad de Logroño. Logroño, 1996.

Subirana, J., Josep Carner: L'exili del mite (1945-1970), Barcelona, 2000.

Toldrà, J., José María Escrivá en Logroño (1915-1925), Madrid, 2007.

Varela Ortega, J., Los amigos políticos. Partidos, elecciones y caciquismo en la Restauración (1875-1900), Madrid, 2001.

Wagner, J., Las reformas más importantes de la Segunda República Española, Múnich, 2015. 


\section{Anexos fotográficos}

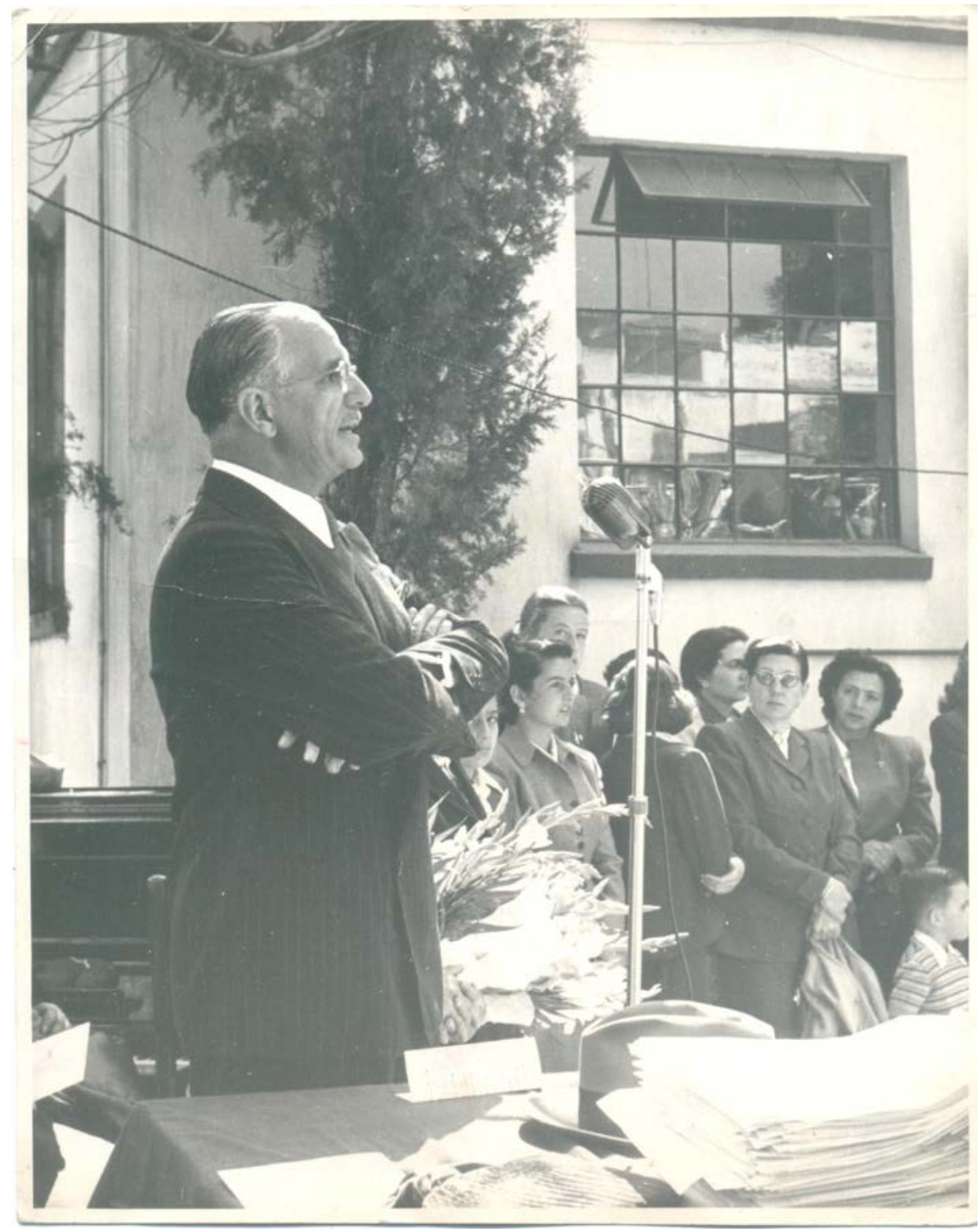

Discurso de Ricardo Vinós en la Academia Hispano Méxicana, circa década 1940 (Archivo familiar Vinós) 


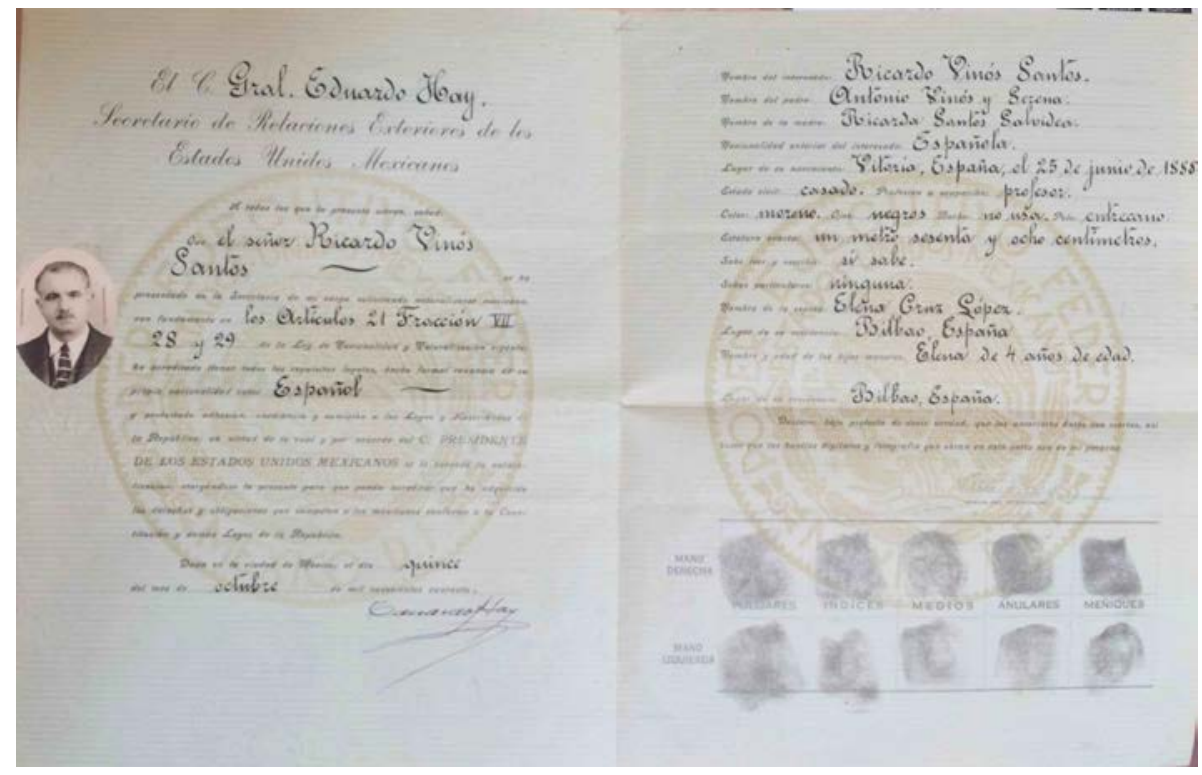

Carta de naturalización de Ricardo Vinós, 15-10-1940 (Archivo familiar Vinós)

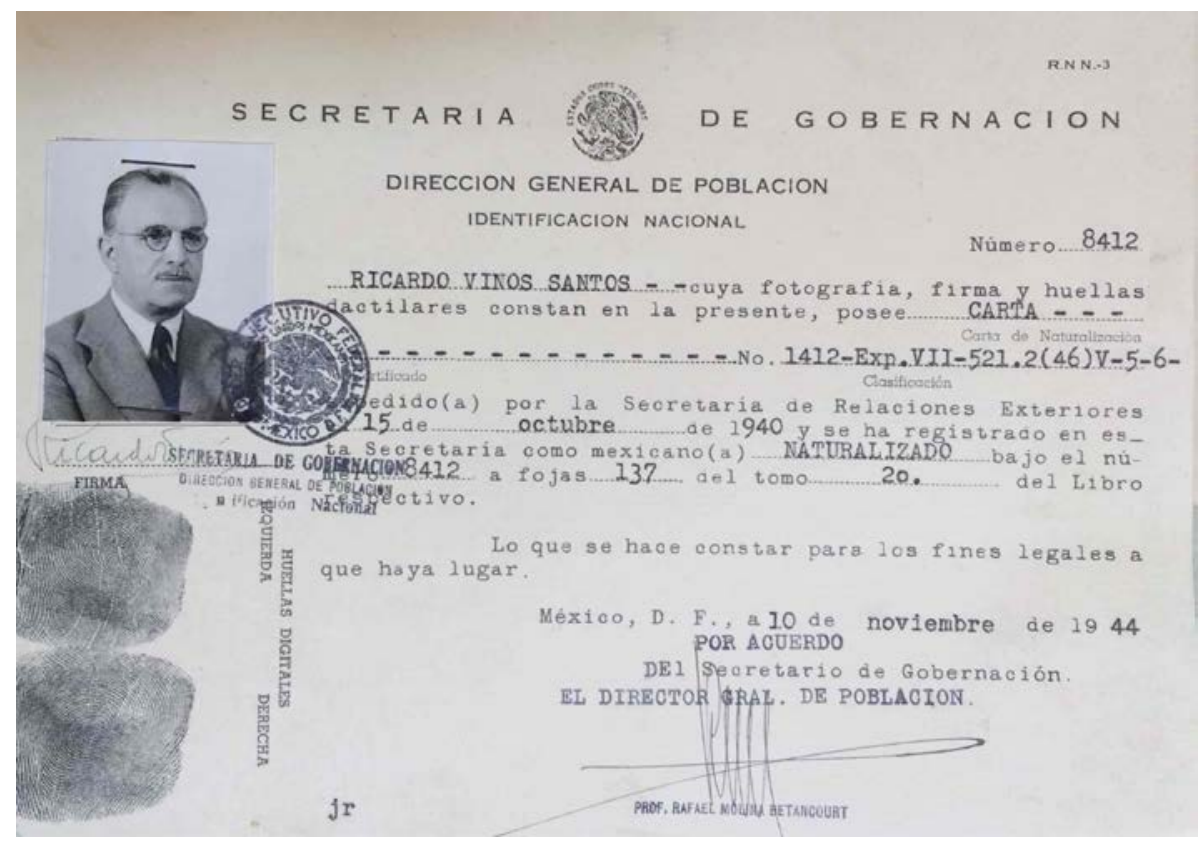

Ficha identificativa de Ricardo Vinós, expedida por el Gobierno de México, 10-11-1944 (Archivo familiar Vinós) 